\title{
A Computational Study of Microflaps with Application to Vibration Reduction in Helicopter Rotors
}

\author{
Li Liu, Ashwani K. Padthe ${ }^{\dagger}$ and Peretz P. Friedmann ${ }^{\ddagger}$ \\ Department of Aerospace Engineering, The University of Michigan, Ann Arbor, MI, 48109, USA
}

\begin{abstract}
A comprehensive study on unsteady effects of oscillating Gurney flaps, or microflaps, has been conducted. Two-dimensional unsteady airloads, lift, moment and drag, due to an oscillating microflap were computed using a compressible Reynolds-Averaged Navier-Stokes (RANS) flow solver. The CFD results were generated with an overset mesh approach that captures oscillatory microflap motion. Three microflap configurations were examined so as to determine the type most suitable in terms of actuation efficiency and practical implementation. Furthermore, a reduced order model (ROM) for the unsteady microflaps was developed based on CFD simulations, using the Rational Function Approximation (RFA) approach. The resulting RFA model is a state-space, time-domain aerodynamic model that accounts for unsteadiness, compressibility and time-varying freestream effect, suitable for use with comprehensive rotorcraft simulations. The agreement between the ROM and direct CFD calculations was found to be excellent even in presence of strong nonlinear flow effects. The approximate model is suitable for incorporation in a comprehensive code, from which the potential of microflaps for active control of vibrations in rotor can be determined. Preliminary studies with open loop control showed that the microflap produces substantial vibration reduction ( $52 \%$ reduction in vertical shear) on a hingeless rotor configuration resembling the MBB BO-105, confirming the control authority of this novel technique.
\end{abstract}

\section{Nomenclature}

\begin{tabular}{|c|c|}
\hline$A$ & Unsteady amplitude \\
\hline$b$ & Airfoil semi-chord $=c / 2$ \\
\hline$c$ & Airfoil chord \\
\hline$c_{f}$ & Microflap chord \\
\hline$C_{T}$ & Rotor thrust coefficient \\
\hline $\mathbf{C}_{0}, \mathbf{C}_{1}, \ldots, \mathbf{C}_{n+1}$ & Rational function coefficient matrices \\
\hline $\mathrm{C}_{d}$ & Total drag coefficient \\
\hline $\mathrm{C}_{l}$ & Lift coefficient \\
\hline $\mathrm{C}_{m}$ & Moment coefficient \\
\hline $\mathrm{C}_{h m}$ & Hinge moment coefficient \\
\hline$D_{0}, D_{1}$ & Generalized flap motions \\
\hline $\mathbf{D}, \mathbf{E}, \mathbf{R}$ & Matrices defined in the RFA model \\
\hline & Generalized load vector \\
\hline $\begin{array}{c}F_{H X 4}, F_{H Y 4}, \\
F_{H Z 4}\end{array}$ & Nondimensional 4/rev hub shears \\
\hline G & Laplace transform of $\mathbf{f}(\bar{t}) U(\bar{t})$ \\
\hline$h$ & Airfoil plunge coordinate \\
\hline h & Generalized motion vector \\
\hline $\mathbf{H}$ & Laplace transform of $\mathbf{h}(\bar{t})$ \\
\hline$k$ & Reduced frequency $=\omega b / U$ \\
\hline
\end{tabular}




\begin{tabular}{ll}
$L_{b}$ & Blade length \\
$L_{c}$ & Spanwise dimension of blade segment with microflap \\
$M_{H X 4}, M_{H Y 4}$, & Mach number \\
\multicolumn{1}{|c}{$M_{H Z 4}$} & Nondimensional 4/rev hub moments \\
$N_{b}$ & Number of rotor blades \\
$n_{L}$ & Number of lag terms \\
$\bar{p}$ & Nondim. surface pressure distribution \\
$\mathbf{Q}$ & Aerodynamic transfer function matrix \\
$\tilde{\mathbf{Q}}$ & Approximation of $\mathbf{Q}$ \\
$s$ & Laplace variable \\
$\bar{s}$ & Nondim. Laplace variable $=s b / U$ \\
$t$ & Time \\
$\bar{t}$ & Reduced time $=\frac{1}{b} \int_{0}^{t} U(\tau) d \tau$ \\
$U(t)$ & Freestream velocity, time-dependent \\
$W_{0}, W_{1}$ & Generalized airfoil motions \\
$\mathbf{x}(t)$ & Aerodynamic state vector \\
$x_{c}$ & Spanwise location of center of microflap segment \\
$\alpha$ & Airfoil angle of attack \\
$\beta_{p}$ & Blade precone angle \\
$\delta_{f}$ & Flap deflection \\
$\gamma$ & Lock number \\
$\gamma_{n}$ & Rational approximant poles \\
$\mu$ & Helicopter advance ratio \\
$\omega$ & Oscillation frequency \\
$\bar{\omega}$ & Nondim. normal velocity distribution \\
$\Omega$ & Rotor angular speed \\
$\omega_{F}, \omega_{L}, \omega_{T}$ & Blade flap, lead-lag and torsional natural frequencies \\
$\phi_{c}$ & Phase angle \\
$\sigma$ & Rotor solidity \\
$\theta_{\mathrm{tw}}$ & Built-in twist angle \\
&
\end{tabular}

\section{Introduction and Background}

High lift devices are widely used to improve the performance of modern aircraft. The Gurney flap originally conceived by Dan Gurney to increase the downward force generated by the spoiler on his race car has emerged as a useful high lift device in aeronautics. Unlike other high lift devices which often consist of a combination of a number of elements linked together, the Gurney flap is a small flap typically 1-5\%c in chord and is attached normal to the airfoil pressure surface at the trailing edge as shown in Fig. 1. Depending on its size and location, the Gurney flap is capable of increasing the maximum lift coefficient of an airfoil by as much as $60 \%$. One of the earliest experimental studies on aerodynamics of a Gurney flap was conducted by Liebeck ${ }^{1}$ who found that the Gurney flap caused the flow to turn around the trailing edge resulting in the formation of two counter-rotating vortices behind the flap, shown in Fig. 1. The flow turning shifts the trailing edge stagnation point to the bottom edge of the microflap thus changing the Kutta condition and increasing the effective camber of the airfoil. Later, these observations have been confirmed using CFD computations. $^{2-5}$ These studies have shown that despite their small size, Gurney flaps can increase the maximum lift, as well as the lift produced at a given angle of attack.

Small Gurney flaps that are deployable as opposed to being permanently fixed are referred to as microflaps in this study. This device has the potential for high bandwidth control with low actuation power requirements, minimal loss in structural stiffness of the wing, and lower wing warping when compared to the conventional control surfaces. Microflaps have been studied for various applications such as control of high aspect ratio flexible aircraft, ${ }^{6,7}$ wing trailing edge vortex alleviation, ${ }^{8-10}$ and most recently for rotorcraft performance enhancement. ${ }^{11-13}$ It was found that the deployable microflaps can increase flutter speed of a highly flexible wing by up to $22 \%{ }^{6}$ Recent studies for fixed wing applications ${ }^{8-10}$ suggest that microflaps can also be used for wake manipulation, by inducing time-varying perturbations that excite vortex instability in the wake. Preliminary studies on rotorcraft performance enhancement ${ }^{11}$ using permanently attached 
Gurney flaps (of size less than 2\%c) have been also conducted. The effect of Gurney flaps on the airfoil lift and drag was modeled as a curve fit of experimental results obtained for flap having various sizes in terms of airfoil chord. Wind-tunnel tests conducted on a model helicopter confirmed that Gurney flaps may have beneficial effects on rotorcraft performance. More recently, deployable microflaps have been studied with active control strategies to enhance rotorcraft performance. ${ }^{12,13}$ A relatively simple deployment schedule where the microflaps are deployed only on retreating side of the disk was used and the maximum thrust of the rotor was enhanced by $10 \%$.

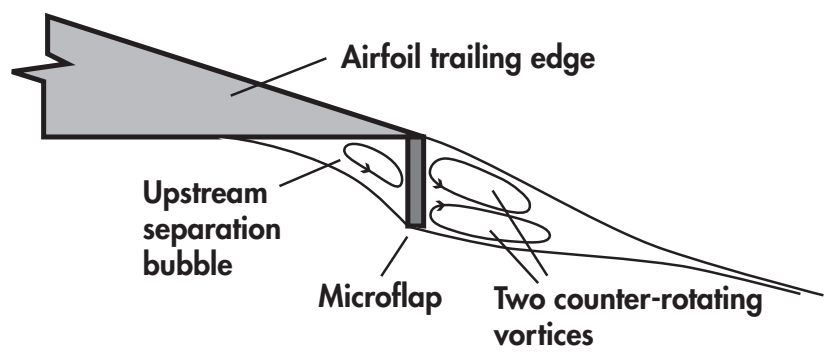

Figure 1. An illustration of the Gurney flap.

During the last decade, various active control approaches, including conventional plain trailing edge flaps, have been shown to be effective for vibration reduction in rotorcraft. ${ }^{14-19}$ The size advantages of the microflaps compared to the plain flaps, which allow high bandwidth actuation with small actuation power, make them a potentially attractive candidate for active control of helicopter vibration. However, the comprehensive assessment of the potential of microflaps for vibration reduction remains to be determined. Therefore, it is essential to develop an accurate and efficient aerodynamic model that can capture the unsteady aerodynamic behavior and characteristics of a microflap that is suitable for combination with comprehensive rotorcraft simulation code. While CFD tools can be used to determine unsteady aerodynamic characteristics of the microflap with reasonable accuracy, the computational costs are prohibitive when conducting parametric trend studies involving active control. Hence, a reduced-order aerodynamic model is essential so as to be able to study vibration reduction characteristics of microflaps for rotary wing applications. An aerodynamic model based on linear potential flow theory is not suitable for modeling microflap aerodynamics due to the inherent nonlinear nature of the flow behind a fully deployed microflap. The overall complexity of this unsteady aerodynamic problem implies that a CFD based approach is required. Also, the reducedorder aerodynamic model has to be expressed in time domain and in the form of algebraic or differential equations that are compatible with the structural equations of motion used in a comprehensive rotorcraft simulation code. The Rational Function Approximation (RFA) approach has been used in the past to generate a Laplace transform or state variable representation of the unsteady aerodynamics of a wing section, for fixed wing applications ${ }^{20-23}$ as well as rotary wing applications. ${ }^{24}$ Myrtle and Friedmann ${ }^{24}$ employed a $^{2}$ doublet-lattice (DL) method to obtain unsteady aerodynamic loads in the frequency domain, combined with the RFA method to convert these loads to the time domain. The RFA model is an unsteady, compressible state-space aerodynamic model, which has several important advantages: 1) it allows a convenient combination of the aerodynamics with the structural dynamic model; 2) it facilitates the solution procedure of the combined system governed by equations with periodic coefficients, using numerical integration; and 3) it provides a degree of computational efficiency required by the implementation of active control techniques such as trailing edge flaps. The RFA model has been implemented in a comprehensive rotorcraft simulation code used in several computational studies involving the effect of active flaps on helicopter vibration and noise reduction, as well as performance enhancement. ${ }^{15,18,25}$ The DL method is based on linear potential flow theory and thus cannot predict the drag coefficient or account for the airfoil thickness effects. Clearly, the flow characteristics behind a fully deployed microflap cannot be determined by the DL method. To overcome these shortcomings, in this study a compressible unsteady Reynolds-Averaged Navier-Stokes CFD solver is used instead of the DL method to generate the frequency domain responses.

The overall objectives of this study are to enhance our understanding of the aerodynamic effects of the microflaps under both steady and dynamic conditions and develop a CFD based nonlinear reducedorder aerodynamic model for microflaps that is suitable for incorporation into a comprehensive rotorcraft simulation. The specific objectives are:

1. Use CFD to conduct a numerical investigation of the microflap under steady and dynamic conditions, 
and determine the effects of the microflap on lift, moment, and drag coefficients of a 2D airfoil.

2. Study and compare the aerodynamic properties of various oscillating microflap configurations using time-accurate Navier-Stokes simulations and identify the configuration most suitable for rotorcraft applications.

3. Develop a CFD based nonlinear reduced-order aerodynamic model for the microflap configuration that is suitable for incorporation into a comprehensive rotorcraft simulation code.

4. Combine the reduced-order microflap aerodynamic model with comprehensive rotorcraft simulation code, and examine the potential of the microflap for helicopter vibration reduction, in the open loop mode, using numerical simulation.

Clearly, achieving these goals will substantially advance the understanding of the physics of microflaps, and allow one to assess the potential of microflap as a viable device for active control of vibrations in rotorcraft.

\section{The CFD Solver and Grid Geometries}

The CFD results generated in this study are obtained using CFD $++^{26,27}$ developed by METACOMP Technologies. The CFD++ code is capable of solving the compressible unsteady Reynolds-Averaged NavierStokes equations. It uses a unified grid methodology that can handle a variety of structured, unstructured, multi-block meshes and cell types, including patched and overset grid features. Spatial discretization of the Navier-Stokes equations is based on a second order multi-dimensional Total Variation Diminishing (TVD) scheme. ${ }^{28}$ For temporal discretization an implicit algorithm with dual time-stepping and multigrid acceleration is used. Dual time-stepping schemes are constructed by appending a pseudo time derivative term and using subiterations for improved accuracy. Multigrid acceleration employs a hierarchy of coarsening grids to speed the convergence. Several turbulence models are available in $\mathrm{CFD}++$, ranging from 1-equation to 3 -equation transport models.

In the present study, both steady and time-accurate flow simulations are carried out to examine the aerodynamics of the microflap combined with a NACA0012 airfoil; the main emphasis is on unsteady effects of the oscillating microflap. In order to identify a suitable microflap configuration for practical implementation, three candidate configurations are examined and compared for their effectiveness in generating unsteady airloads. The grids employed for these configurations are shown in Figs. 2(a)-2(c). Grids for the various microflap configurations are generated using the overset approach, which is particularly convenient for modeling complex geometries and moving components with large relative motions. The first configuration consists of a microflap that slides in and out from a cavity located at a given distance before the sharp trailing edge of the airfoil, as shown in Fig. 2(a). This configuration is similar to that employed in Refs. 5 and 29. The grid for this configuration is obtained by successively combining several overset refinement grids for the microflap and the cavity, as shown in the figure. The second configuration consists of a microflap capable of moving up and down behind the blunt trailing edge of the airfoil, shown in Fig. 2(b). The blunt trailing edge is created by removing the aft portion of the airfoil such that there is enough space for accommodating the microflap when in the fully retracted position. The third microflap configuration has a rotational hinge at the trailing edge and thus it resembles a miniature plain flap, as shown in Fig. 2(c).

All the computations are carried out by solving RANS equations and assuming fully turbulent flow. The computational domain is a C-grid with far field boundary extending to 50 chord lengths in all directions. A distance of 30-50 chord lengths is typically used in order to minimize the effects of numerical reflection from the far field boundary. The grids are clustered at the airfoil wall boundaries such that the dimensionless distance $y^{+}$of the first grid point off the wall is less than 1 and the equations are solved directly to the walls without assuming any wall functions.

\section{Reduced-Order Model for Microflap}

This section describes the development of the RFA based ROM for microflaps. It is a state-space, time domain model that accounts for flow unsteadiness and compressibility. In our earlier research, RFA based aerodynamics were developed for modeling the aerodynamic response of a two-dimensional airfoil/trailing edge flap combination. This unsteady aerodynamic model was implemented in a comprehensive rotorcraft simulation code AVINOR (Active Vibration and Noise Reduction) which has been carefully validated. ${ }^{18,24,30,31}$ 


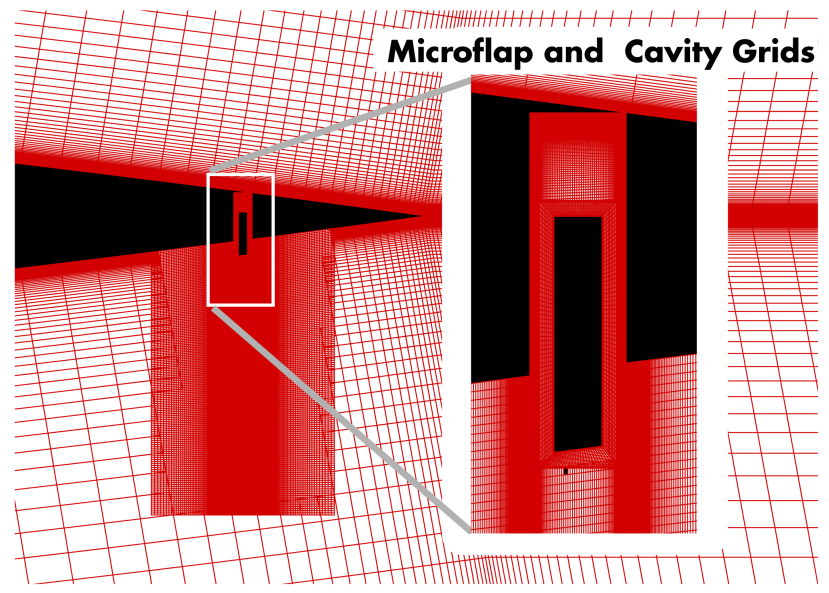

(a) Sliding microflap in a cavity

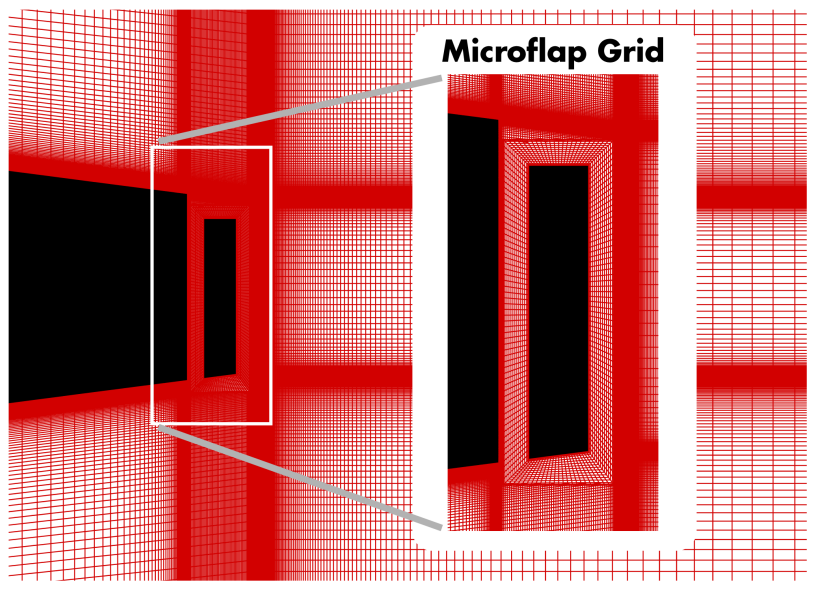

(b) Sliding microflap at blunt trailing edge

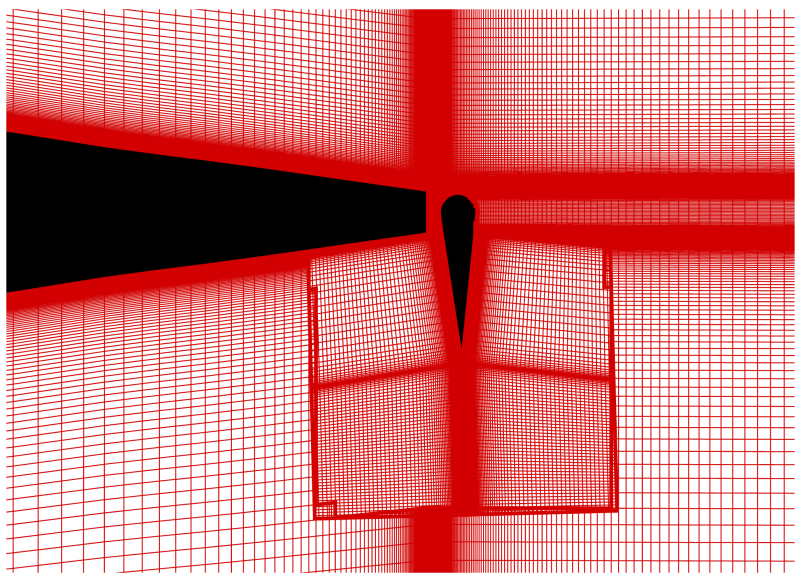

(c) Rotating microflap resembling a plain flap

Figure 2. Three candidate microflap configurations. 
Recently, the accuracy of this model was also verified by comparing the RFA predictions with CFD based results for the unsteady aerodynamic loads on two-dimensional airfoil/oscillating flap combinations over a wide range of aerodynamic conditions representative of rotorcraft applications. ${ }^{32,33}$ The RFA model was found to provide reasonable estimates of unsteady airloads for Mach numbers below $\mathrm{M}=0.70$. Clearly the approximate RFA based airloads require a very small amount of computer time when compared to CFD based results.

\section{III.A. Brief description of the RFA model}

The RFA model developed in Ref. 24 is based on Roger's approximation ${ }^{20}$ for representing aerodynamic loads in the Laplace domain

$$
\mathbf{G}(\bar{s})=\mathbf{Q}(\bar{s}) \mathbf{H}(\bar{s})
$$

where $\mathbf{G}(\bar{s})$ and $\mathbf{H}(\bar{s})$ represent Laplace transforms of the generalized aerodynamic load and generalized motion vectors, respectively. The aerodynamic transfer matrix $\mathbf{Q}(\bar{s})$ is approximated using the Least Squares approach with a rational expression of the form

$$
\mathbf{Q}(\bar{s})=\mathbf{C}_{0}+\mathbf{C}_{1} \bar{s}+\sum_{n=1}^{n_{L}} \frac{\bar{s}}{\bar{s}+\gamma_{n}} \mathbf{C}_{n+1} .
$$

The last equation is usually denoted as Roger's approximation. These poles are assumed to be positive valued to produce stable open loop roots, but are otherwise non-critical for the approximation. The arbitrary motions of the airfoil and the flap are represented by four generalized motions shown in Fig. 3. The normal

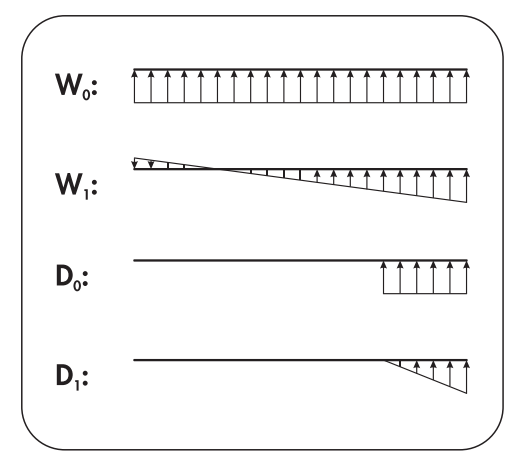

Figure 3. Normal velocity distribution corresponding to generalized airfoil and flap motions.

velocity distributions shown in Fig. 3 correspond to two generalized airfoil motions (denoted by $W_{0}$ and $W_{1}$ ) and two generalized flap motions (denoted by $D_{0}$ and $D_{1}$ ). In order to find the Least Squares approximants for the aerodynamic response, tabulated oscillatory airloads, i.e. sectional lift, moment and hinge moment, have to be obtained corresponding to each of the four generalized motions. In the original RFA implementation, ${ }^{24}$ the oscillatory airloads in the frequency domain were obtained from a two-dimensional doublet lattice (DL) solution $^{34}$ of Possio's integral equation ${ }^{35}$ which relates pressure $\bar{p}$ to surface normal velocity $\bar{w}$ as shown below in Eq. (3)

$$
\bar{w}(x)=\frac{1}{8 \pi} \int_{-1}^{1} \bar{p}(\zeta) K(M, x-\zeta) d \zeta,
$$

where $K$ is the kernel function. This approach was found to be very efficient for generating a set of aerodynamic response data for the generalized motions of airfoil/flap combination. The frequency domain information is generated for an appropriate set of reduced frequencies and Mach numbers, encompassing the entire range of unsteady flow conditions encountered in practical applications. The state space representation of the RFA aerodynamic model requires a generalized motion vector $\mathbf{h}$ and produces a generalized load vector 
f, defined as:

$$
\mathbf{h}=\left\{\begin{array}{c}
W_{0} \\
W_{1} \\
D_{0} \\
D_{1}
\end{array}\right\} \quad \text { and } \quad \mathbf{f}=\left\{\begin{array}{c}
\mathrm{C}_{l} \\
\mathrm{C}_{m} \\
\mathrm{C}_{h m}
\end{array}\right\}
$$

The Laplace transform representation in Eq. (1) relates the generalized motion to the generalized forces, through the following expressions

$$
\mathbf{G}(\bar{s})=\mathcal{L}[\mathbf{f}(\bar{t}) U(\bar{t})] \quad \text { and } \quad \mathbf{H}(\bar{s})=\mathcal{L}[\mathbf{h}(\bar{t})]
$$

The reduced time $\bar{t}$ is defined such that unsteady freestream effects can be properly accounted for, ${ }^{24}$ and may be interpreted as the distance measured in semi-chords. The rational approximant $\tilde{\mathbf{Q}}$ in Eq. (2) can be transformed to the time domain using the inverse Laplace transform, which yields the final form of the state space model, given below

$$
\begin{aligned}
\dot{\mathbf{x}}(t) & =\frac{U(t)}{b} \mathbf{R x}(t)+\mathbf{E} \dot{\mathbf{h}}(t), \\
\mathbf{f}(t) & =\frac{1}{U(t)}\left(\mathbf{C}_{0} \mathbf{h}(t)+\mathbf{C}_{1} \frac{b}{U(t)} \dot{\mathbf{h}}(t)+\mathbf{D x}(t)\right) .
\end{aligned}
$$

and the matrices $\mathbf{D}, \mathbf{R}$ and $\mathbf{E}$ are given by

$$
\begin{aligned}
\mathbf{D}=\left[\begin{array}{llll}
\mathbf{I} & \mathbf{I} & \ldots & \mathbf{I}
\end{array}\right], \mathbf{R} & =-\left[\begin{array}{llll}
\gamma_{1} \mathbf{I} & & & \\
& \gamma_{2} \mathbf{I} & & \\
& & \ldots & \\
& & & \gamma_{n_{L}} \mathbf{I}
\end{array}\right] \\
\mathbf{E} & =\left[\begin{array}{c}
\mathbf{C}_{2} \\
\mathbf{C}_{3} \\
\vdots \\
\mathbf{C}_{n_{L}+1}
\end{array}\right]
\end{aligned}
$$

\section{III.B. Modified RFA model for microflap}

The DL method is based on linear potential flow theory; as a result, the RFA model constructed based on oscillatory responses generated with the DL method loses its validity when significant flow nonlinearities associated with viscous effects or shock wave formation are present. Flow characteristics of a fully deployed microflap are highly nonlinear and therefore cannot be predicted from the DL method. Furthermore, unsteady drag due to the microflap motion, which is important for estimating the performance penalty due to such devices, cannot be obtained from potential flow theory. Therefore, solutions from the compressible unsteady RANS solver CFD++ are used, instead of generating such information from potential flow solvers, thus the strong viscous flow behind a microflap is properly represented and drag estimates are obtained in addition to lift and moment. Note that the generalized load vector $\mathbf{f}$ is now written as

$$
\mathbf{f}=\left\{\begin{array}{c}
\mathrm{C}_{l} \\
\mathrm{C}_{m} \\
\mathrm{C}_{d}
\end{array}\right\}
$$

In this study the precise value of the hinge moment of the microflap was not considered.

In order to account for flow nonlinearities encountered at high Mach number, large angle of attack and flap deflection angle, the RFA model is enhanced by using a technique referred to as model scheduling, ${ }^{36}$ wherein different sets of RFA coefficients are generated at appropriate combinations of the Mach number, angle of attack, and flap deflection angle. This approach resembles the gain scheduling approach used in control system design, commonly employed for control of nonlinear systems. ${ }^{36,37}$ Specifically, the RFA model 
is modified by allowing the coefficient matrices, i.e., $\mathbf{R}, \mathbf{E}, \mathbf{C}_{0}, \mathbf{C}_{1}, \ldots$, to vary with $M, \alpha$, and $\delta_{f}$. The resulting state space model in the time domain is represented as

$$
\begin{aligned}
\dot{\mathbf{x}}(t) & =\frac{U(t)}{b} \mathbf{R}\left(M, \alpha, \delta_{f}\right) \mathbf{x}(t)+\mathbf{E}\left(M, \alpha, \delta_{f}\right) \dot{\mathbf{h}}(t), \\
\mathbf{f}(t) & =\frac{1}{U(t)}\left(\mathbf{C}_{0}\left(M, \alpha, \delta_{f}\right) \mathbf{h}(t)\right. \\
& \left.+\mathbf{C}_{1}\left(M, \alpha, \delta_{f}\right) \frac{b}{U(t)} \dot{\mathbf{h}}(t)+\mathbf{D}\left(M, \alpha, \delta_{f}\right) \mathbf{x}(t)\right) .
\end{aligned}
$$

When constructing a microflap model, two generalized airfoil motions, i.e. $W_{0}$ and $W_{1}$ as shown in Fig. 3 , are used to describe arbitrary airfoil pitch and plunge motion. In terms of classical pitch and plunge coordinates $\alpha$ and $h$, these generalized motions can be expressed as

$$
\begin{aligned}
& W_{0}=U \alpha+\dot{h} \\
& W_{1}=b \dot{\alpha}
\end{aligned}
$$

The description of the airfoil motion is identical to that used in the original RFA model. For the microflap, the concept of normal velocity distributions is no longer meaningful; therefore, the microflap motion is simply characterized by the deflection $\delta_{f}$. Unsteady airloads in response to harmonic motions of $W_{0}, W_{1}$ and $\delta_{f}$ in various reduced frequencies are subsequently generated using CFD. Clearly, this approach accounts for fully unsteady, combined airfoil and microflap motions.

\section{Results and Discussions}

For all computations presented in this section the Reynolds number is $3.36 \times 10^{6}$. The $\mathrm{k}-\omega$ shear-stress transport (SST) model ${ }^{38}$ is used for turbulence modeling due to its good performance in separated flow. The flow is first allowed to reach steady state, before conducting time-dependent simulations for various oscillating microflap configurations. The simulations are conducted using the overset mesh approach based on the computational grids discussed earlier. The time-accurate simulations utilize time steps such that at least 250 points are resolved per flap oscillation cycle, and at least four cycles are computed to ensure that periodicity has been achieved.

\section{IV.A. Steady and oscillating microflaps}

The flow conditions and oscillating frequencies for the unsteady microflap simulations are selected to be representative of the aerodynamic environment encountered during the vibration control of a typical hingeless rotor, that resembles an MBB BO-105. The free stream Mach number is 0.51 . The unsteady microflap is examined at two values of reduced frequencies, namely, $k=0.0688$ and 0.1376 , based on airfoil chord. These oscillatory frequencies correspond to approximately $2 / \mathrm{rev}$ and 4/rev for the MBB BO-105 rotor, which has four blades, and where such harmonics are usually employed for the active control of vibrations. The airfoil is set to a $0^{\circ}$ mean angle of attack. Results for various oscillating microflap configurations on a NACA0012 airfoil are presented next.

The first configuration has a microflap sliding in and out of a cavity, located at $6 \%$ c from the sharp trailing edge of the airfoil, depicted in Fig. 4. The microflap is $1.5 \% \mathrm{c}$ in height and other relevant dimensions are also shown in the figure. Microflap deflection $\delta_{f}$ is defined as the distance from the top edge of the flap to the surface of the airfoil as illustrated in Fig. 4. The microflap starts from a completely retracted position, i.e., $\delta_{f}=0$ and slides out of the cavity to attain a maximum deflection of $\delta_{f}=1.5 \%$ c. Simulations are conducted for the microflap undergoing sinusoidal oscillations, given by

$$
\delta_{f}=A(1-\cos \omega t),
$$

where $A=0.75 \% \mathrm{c}$ is the amplitude and $\omega$ is the frequency of oscillation. This deflection time history is shown in Fig. 5 for an oscillating frequency of $k=0.0688$.

In Fig. 6(a) the unsteady lift is plotted as a function of non-dimensional reduced time $\bar{t}$, while in Fig. 6(b) the lift is plotted as a function of the microflap deflection $\delta_{f}$. For comparison purposes, all the figures in this section showing unsteady aerodynamic coefficients also display the steady force coefficients for a fully 


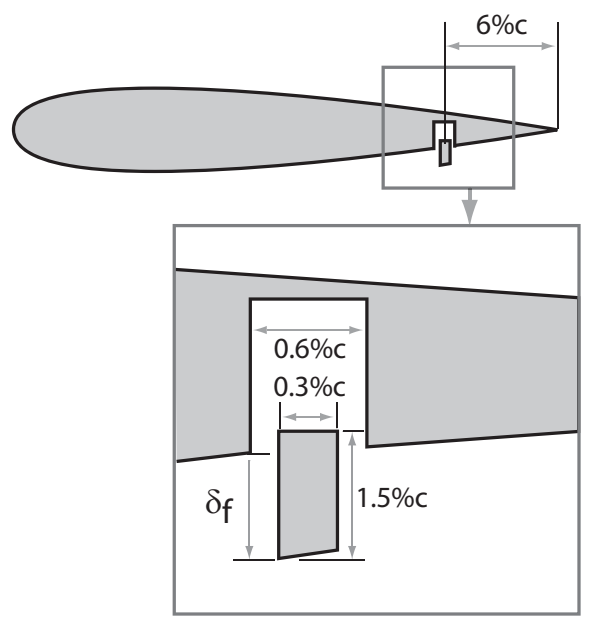

Figure 4. Oscillating microflap in a cavity.

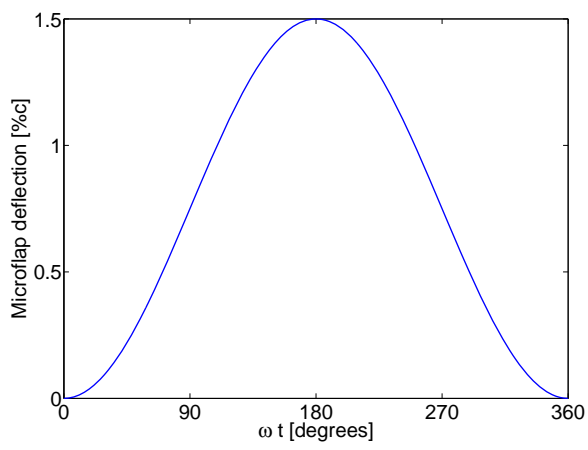

Figure 5. Time history of unsteady microflap deflection.

deployed microflap, indicated in the figure by ' $\delta_{f}=1.5 \% c$ '. Similarly, steady values of lift when the microflap is fully retracted is indicated by ' $\delta_{f}=0 \% c$ '. The maximum unsteady lift $\mathrm{C}_{l}$ at $\mathrm{k}=0.0688$ is significantly less than the steady lift, indicating lift deficiency due to unsteady effects. Oscillatory amplitude of the unsteady lift is further reduced when $k$ is increased from 0.0688 to 0.1376 . Variations of the unsteady moment coefficients with reduced time and microflap deflection are shown in Figs. 7(a) and 7(b), respectively. From these figures, it can be seen that the effect of flow unsteadiness on the magnitude of the moment is fairly small. The drag coefficients as functions of reduced time and the microflap deflection are shown in Figs. 8(a) and 8(b), respectively. Comparison of the unsteady effect on the oscillating amplitude at two frequencies shown in Fig. 8(a) indicates that microflaps oscillating at higher reduced frequencies produce a larger unsteady drag amplitude, a behavior that is contrary to the case shown earlier for unsteady lift.

A time lag in lift coefficient can be observed while the microflap is sliding out of the cavity, as the flow takes time to develop and form a vortical structure behind the microflap. This nonlinear behavior is evident in the time history plots of the aerodynamic coefficients which appear to have nonharmonic components, despite the fact that the microflap motion is purely harmonic, as given by Eq. (12).

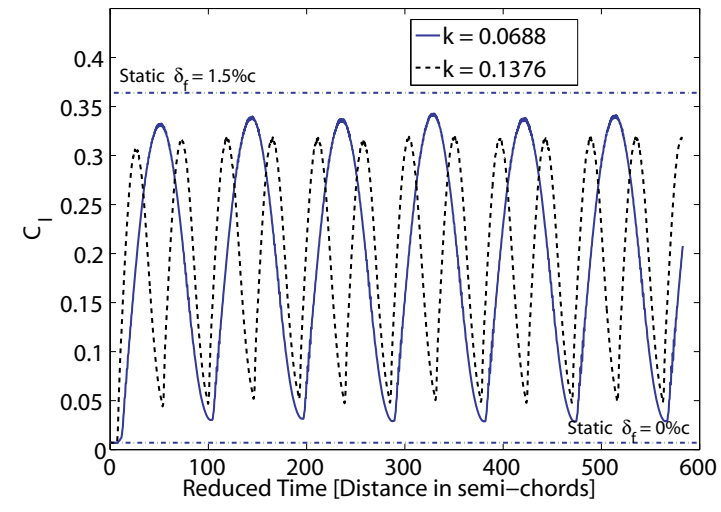

(a) $\mathrm{C}_{l}$ vs. $\bar{t}$

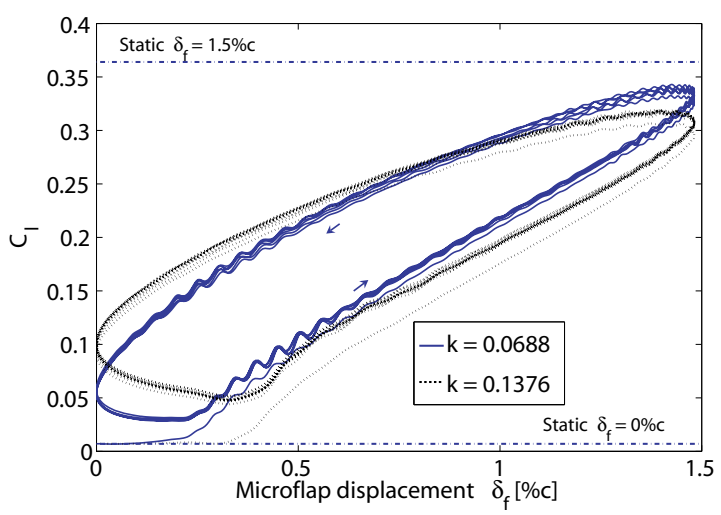

(b) $\mathrm{C}_{l}$ vs. $\delta_{f}$

Figure 6. Unsteady lift for a $1.5 \%$ c microflap at two reduced frequencies for the sharp TE configuration; $M=0.51$.

The results for the second configuration consisting of an oscillating microflap located at the blunt trailing edge of the airfoil, shown in Fig. 9, are presented next. The blunt trailing edge is created by removing the aft $6 \%$ of the airfoil. This configuration has a potential advantage over the previous configuration because for this case the microflap can be deflected both up and down from its neutral position. Furthermore, this configuration may be easier to implement from a practical point of view, regarding the placement of the actuation mechanism. For comparison purposes, the simulations were performed only with downward 


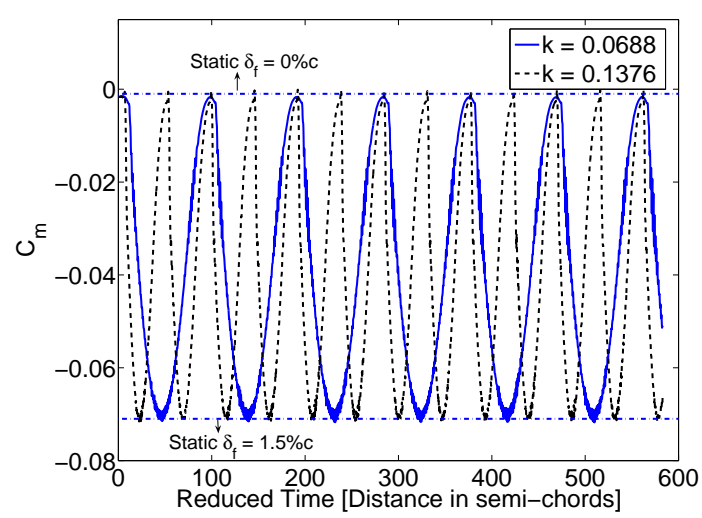

(a) $\mathrm{C}_{m}$ vs. $\bar{t}$

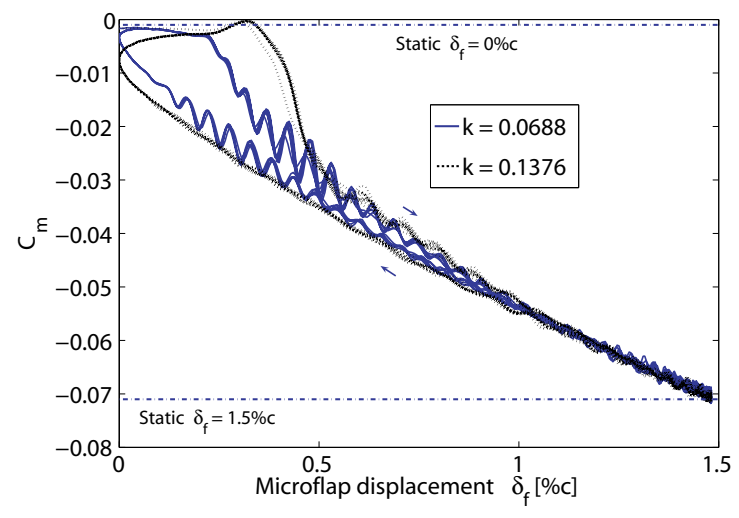

(b) $\mathrm{C}_{m}$ vs. $\delta_{f}$

Figure 7. Unsteady moment for a $1.5 \%$ microflap at two reduced frequencies for the sharp TE configuration; $\mathrm{M}=$ 0.51 .

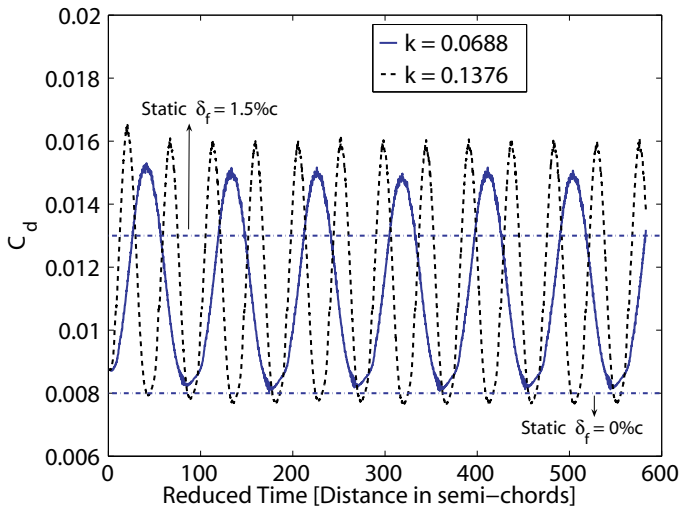

(a) $\mathrm{C}_{d}$ vs. $\bar{t}$

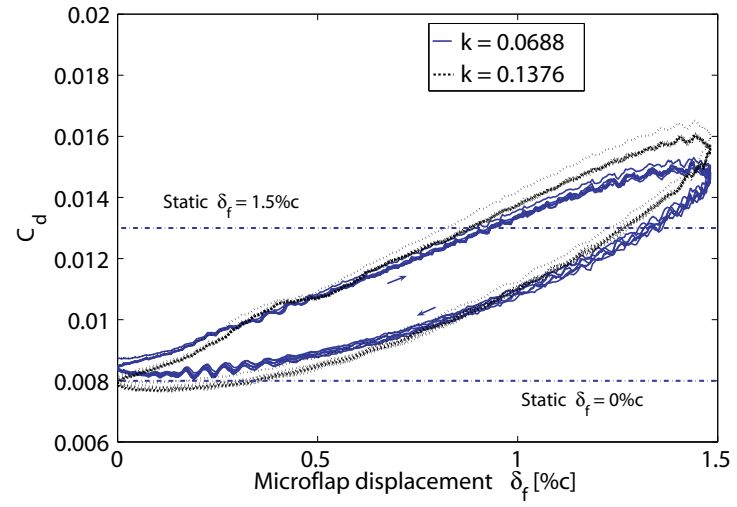

(b) $\mathrm{C}_{d}$ vs. $\delta_{f}$

Figure 8. Unsteady drag for a $1.5 \%$ microflap at two reduced frequencies for the sharp $\mathrm{TE}$ configuration; $\mathrm{M}=0.51$. 
motion of the microflap, with similar flap deflection schedule to that given in Eq. (12). The flow parameters were also identical to those used in the previous configuration.

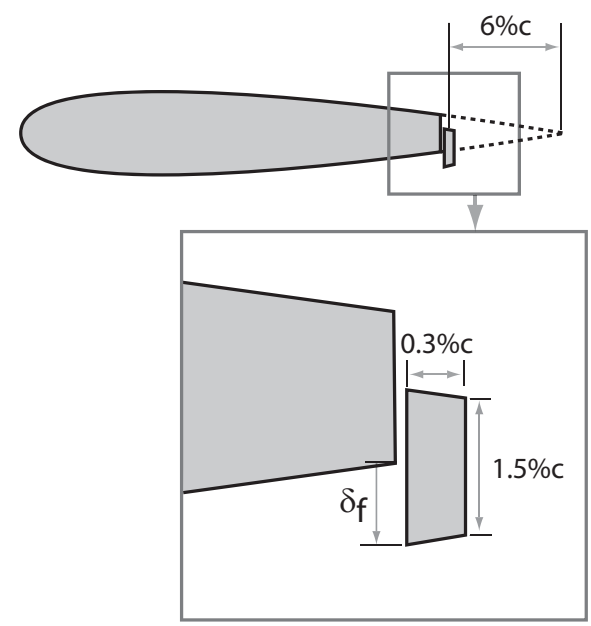

Figure 9. Oscillating microflap at blunt trailing edge.

Unsteady lift, moment and drag due to the microflap motion are presented in a similar manner to those given earlier for the sharp TE configuration. First the lift coefficient is plotted against the reduced time and $\delta_{f}$ in Figs. 10(a) and 10(b), respectively. The unsteady moments time histories are shown in Figs. 11(a) and 11(b). Similar plots for the drag coefficient are also given in Figs. 12(a) and 12(b). Again the effect of flow unsteadiness associated with the two reduced frequencies used in the computations, display characteristics similar to those noted for the first configuration.

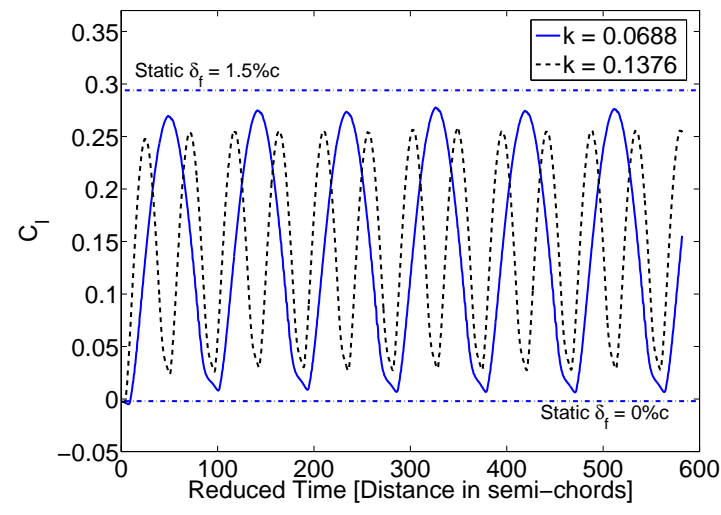

(a) $\mathrm{C}_{l}$ vs. $\bar{t}$

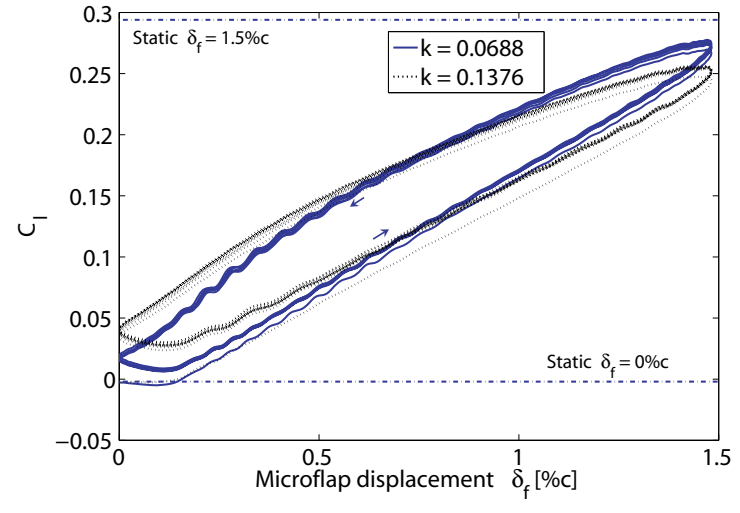

(b) $\mathrm{C}_{l}$ vs. $\delta_{f}$

Figure 10. Unsteady lift for a $1.5 \%$ c microflap oscillating at two reduced frequencies for the blunt TE configuration; $\mathrm{M}=0.51$.

The third flap configuration selected was a microflap that resembles a plain flap rotating at the TE, as illustrated in Fig. 13. This configuration may be difficult to implement in practice due to space limitations for accommodating the actuators and hinges. Furthermore, to have a meaningful comparison with earlier results, the microflap is only rotated downwards between $\delta_{f}=0^{\circ}$ and $\delta_{f}=90^{\circ}$. Again the simulated flow conditions are identical to that used for the previous two configurations. For this configuration, the pressure contour plot near the trailing edge of the airfoil is shown in Fig. 14 along with the evolution of streamlines during one cycle of microflap oscillation. Figure 14 clearly illustrates the development of the vortical structure behind the microflap which consists of two counter-rotating vortices when the microflap is fully deployed, and the pattern displayed in Fig. 14(b) is similar to that found on static Gurney flaps. ${ }^{3,39}$

Comparisons of the unsteady lift, moment and drag for all three oscillating microflap configurations are shown in Fig. 15, for $\mathrm{k}=0.0688$ at the free stream Mach number of $M=0.51$. From Fig. 15, it can be seen 


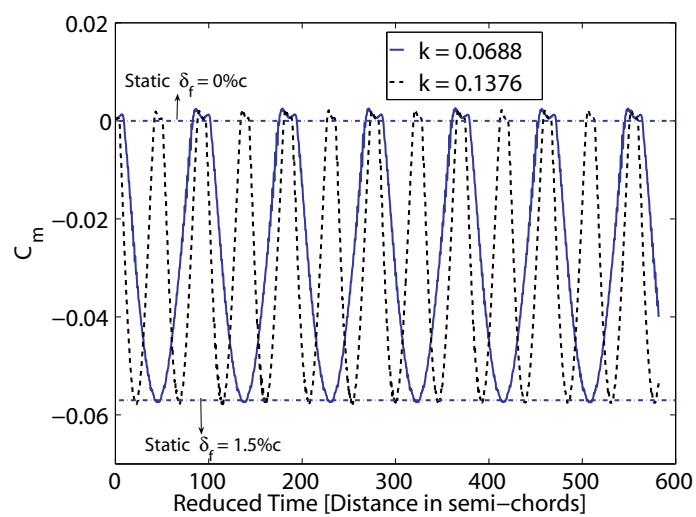

(a) $\mathrm{C}_{m}$ vs. $\bar{t}$

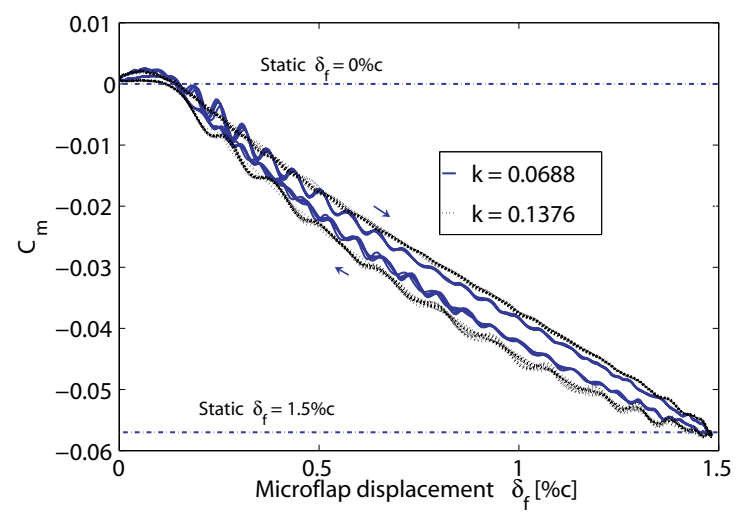

(b) $\mathrm{C}_{m}$ vs. $\delta_{f}$

Figure 11. Unsteady moment for a $1.5 \%$ c microflap oscillating at two reduced frequencies for the blunt TE configuration; $\mathrm{M}=0.51$.

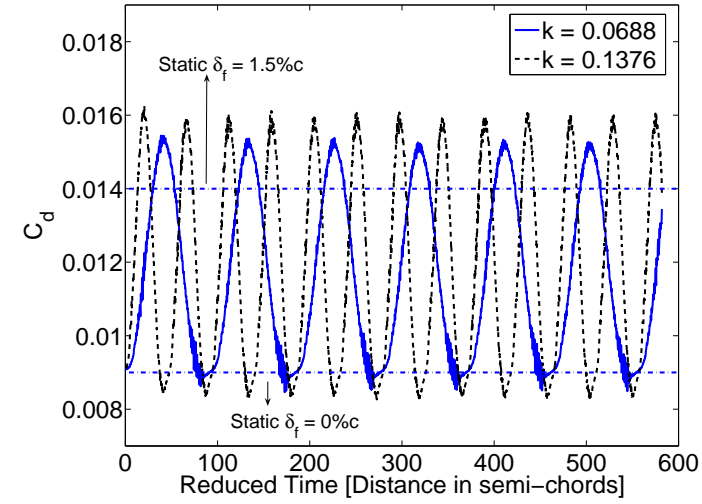

(a) $\mathrm{C}_{d}$ vs. $\bar{t}$

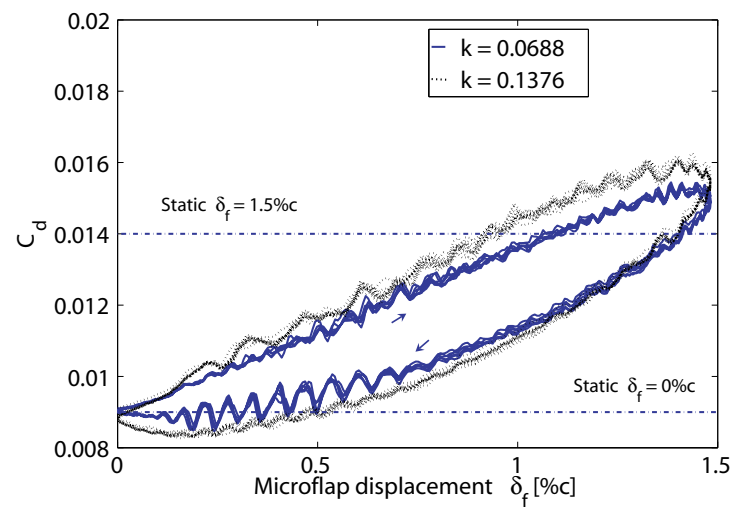

(b) $\mathrm{C}_{d}$ vs. $\delta_{f}$

Figure 12. Unsteady drag for a $1.5 \%$ c microflap oscillating at two reduced frequencies for the blunt TE configuration; $\mathrm{M}=0.51$.

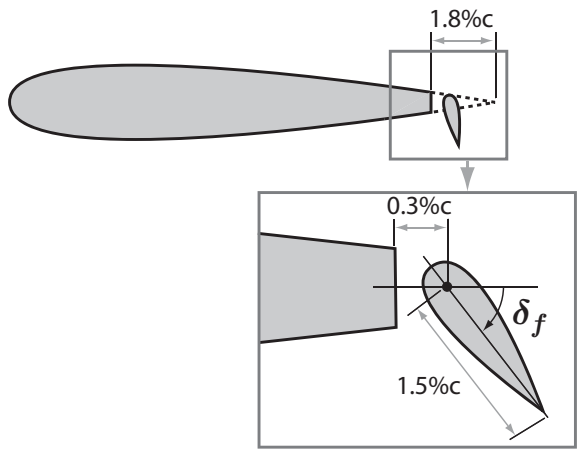

Figure 13. Illustration of a rotating microflap resembling a plain flap. 


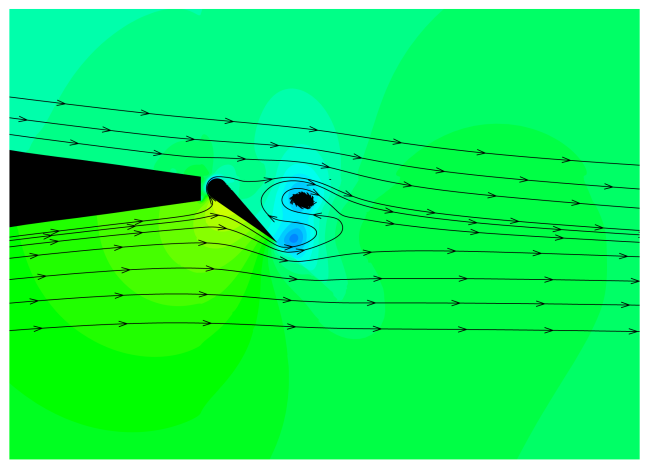

(a) $\mathrm{t}=\frac{1}{4} \mathrm{~T}$

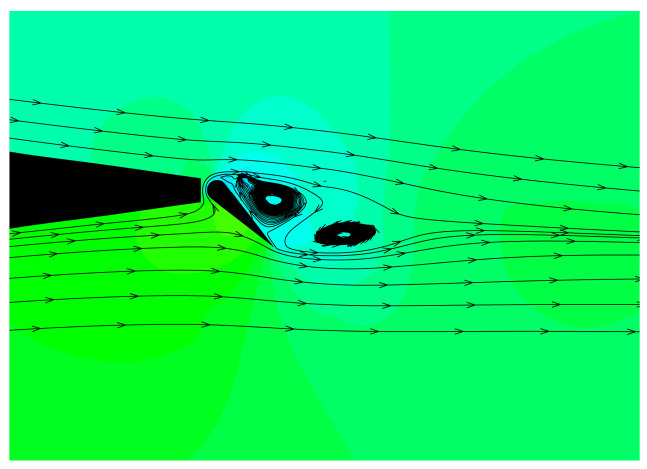

(c) $\mathrm{t}=\frac{3}{4} \mathrm{~T}$

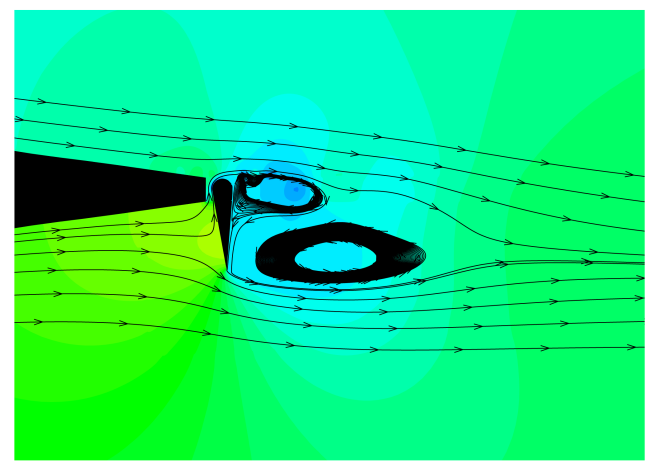

(b) $\mathrm{t}=\frac{1}{2} \mathrm{~T}$

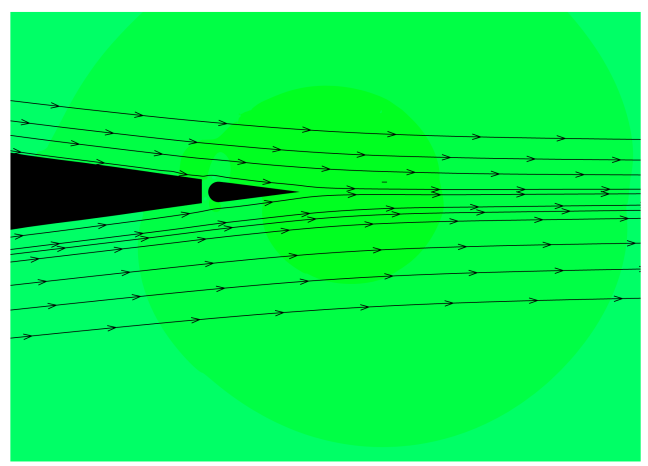

(d) $\mathrm{t}=1 \mathrm{~T}$

Figure 14. Pressure contours and streamlines showing evolution of vortical structure during one cycle of oscillation behind the plain microflap at $\mathbf{M}=\mathbf{0 . 5 1}$ and $\alpha=0^{\circ}$. 
that the maximum lift when using the blunt TE configuration is approximately $20 \%$ lower than that obtained with the sharp TE configuration. The overall unsteady lift coefficient for the plain microflap configuration is similar to that for the blunt TE configuration. Except that at the maximum deflected position the plain microflap generates $17 \%$ less lift than that obtained with the blunt TE configuration. The reason for the decrease in the maximum lift can be attributed to the fact that the plain microflap in the $90^{\circ}$ deflected position does not have the effective length of $1.5 \% \mathrm{c}$ microflap, because the finite thickness of the airfoil trailing edge (see Fig. 13) reduces its effective length. Comparison of moment coefficients reveals similar trends, that are again due to reduction in the effective length.

Figure 15(c) indicates that both sliding microflap configurations generate similar amounts of drag. By comparison, the plain microflap configuration produces the smallest amount of drag with a $7 \%$ decrease in the peak value when compared to the other two configurations. This reduction in drag is also due to the lower effective length of the plain microflap.

Variations of the lift-to-drag ratio in one flap cycle associated with the three configurations are shown in Fig. 16, together with the normalized flap deflection time history. The configuration with the best L/D ratio is most desirable from a purely aerodynamic point of view. The results shown in Fig. 16, indicate that the sharp trailing edge configuration yields the best L/D ratio, while the blunt trailing edge configuration is the worst. Overall, the sharp trailing edge configuration may be the best compromise between the aerodynamic benefits and the ease of implementation, provided that the structural strength of the blade is not adversely affected.

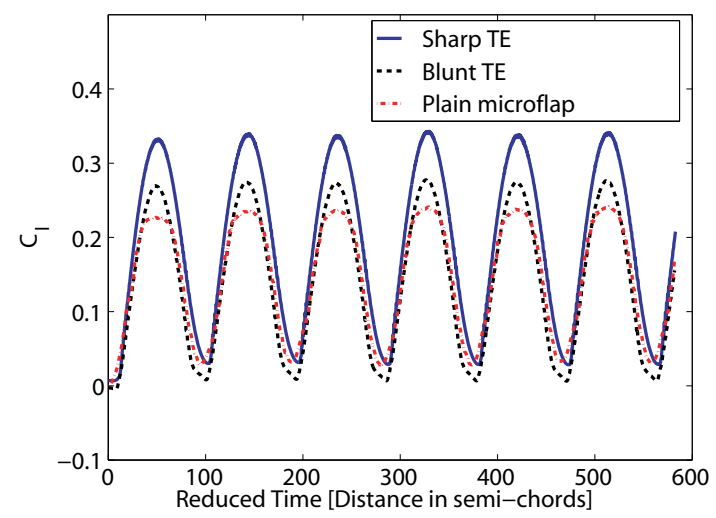

(a) Lift coefficient

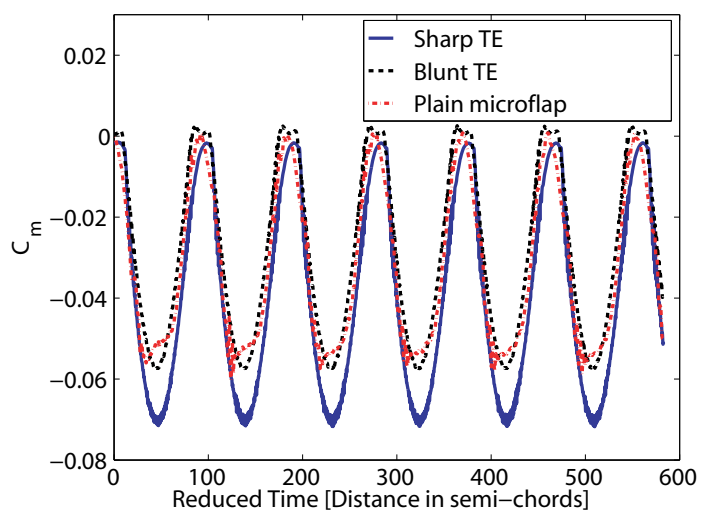

(b) Moment coefficient

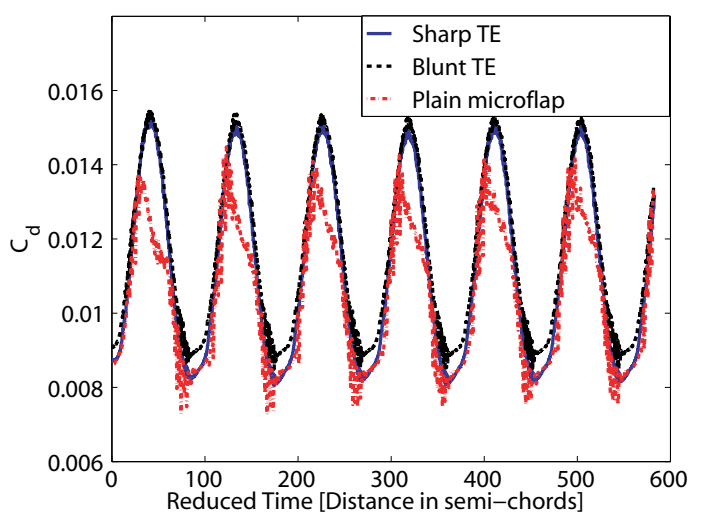

(c) Drag coefficient

Figure 15. Comparison of unsteady lift, moment and drag for three different microflap configurations.

A major disadvantage of the sharp trailing edge configuration is that it can only be deployed in one direction. By comparison, the plain microflap and the blunt trailing edge configurations allow for both upward and downward deflections of the microflap. To assess the potential benefits of having a microflap 


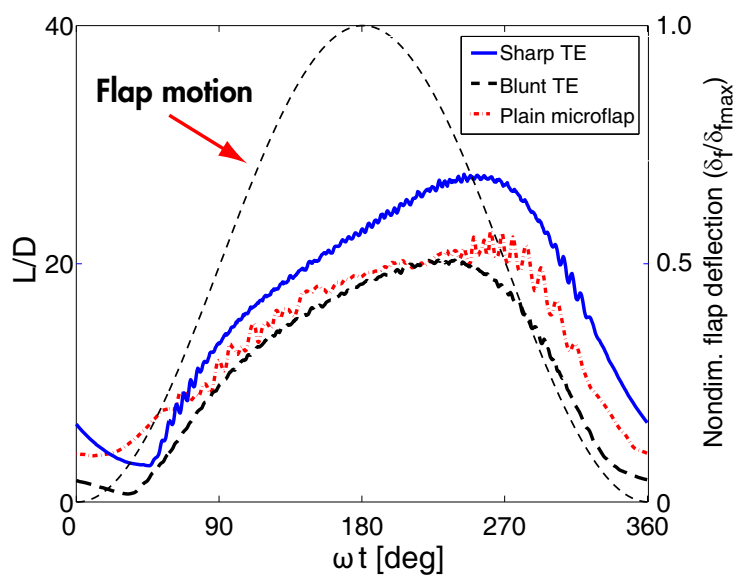

Figure 16. Comparison of lift-to-drag ratio obtained for all three microflap configurations; $\mathrm{M}=0.6$ and $\mathrm{k}=0.0688$.

that can be deployed in both directions additional simulations were conducted for the two configurations undergoing the entire range of microflap motion, using the following deflection profile

$$
\delta_{f}=A \sin (\omega t)
$$

In Eq. (13) the amplitude $A$ is $1.5 \%$ c for the blunt trailing edge configuration, and $A=90^{\circ}$ for the plain microflap configuration. The unsteady sectional airloads for the two configurations are compared in Fig. 17(a)17(c). These results show that an upward deflection of the microflap generates a pitch-up moment on the airfoil and a downward deflection generates a pitch-down moment. The unsteady moment in Fig. 17(b) may be compared to that shown in Fig. 15(b), where the sharp trailing edge microflap configuration can only generate a pitch-down moment. The ability to generate both pitch-up and pitch-down moments may prove important for active control of torsionally soft rotor blades.

\section{IV.B. Reduced Order Model for Microflaps}

Reduced order models for sectional aerodynamic responses of microflaps are presented in this section. The ROMs are constructed using Eq. (9) where the frequency domain data are based on CFD computations. The microflap ROM developed using frequency response data generated with CFD is referred to as the CFD+RFA model. The microflap configuration employed here is the sharp trailing edge type with a $1.5 \% \mathrm{c}$ microflap, as shown in Fig. 4. The simulations were conducted for various reduced frequencies ranging from $0.06-0.2$, at the Mach number of 0.6 and the airfoil angle of attack $\alpha=0^{\circ}$.

Figures 18(a), (d) and (g) show the unsteady lift variation for the microflap oscillating motion given by Eq. (12). The direct CFD results, indicated by the circles, are compared to the ROM results represented by the full line. The agreement for all reduced frequencies shown here is excellent, and the ROM captured the unsteady lift deficiency effect when the reduced frequency is increased from 0.06 to 0.2. Similarly, the unsteady moment is also captured accurately by the ROM, as shown in Figs. 18(b), (e) and (h). The unsteady drag predictions, shown in Figs. 18(c), (f) and (i), are less accurate since the ROM predictions exhibit some error in the mean values (less than 10\%) when compared to the CFD calculations. This error in the mean value predictions may be reduced by using more CFD fitting points when generating the reduced order model. Nevertheless, it is evident from Fig. 18 that the oscillating amplitudes of lift, moment and drag coefficients due to the microflap motion are captured quite well. Overall, for all the reduced frequencies considered the ROMs for the microflap provide excellent accuracy when compared to direct CFD calculations, and clearly, these are obtained at a fraction of the computational cost. Furthermore, the ability of the ROM to account for unsteadiness in drag is a substantial improvement when compared to a quasisteady drag model developed earlier for flapped airfoils. ${ }^{33}$

\section{IV.C. Vibration Reduction with the Microflap}

The potential of microflap for vibration reduction on a hingeless rotor is studied by incorporating the ROM, described in the previous section, in a comprehensive rotorcraft simulation code. The microflap 


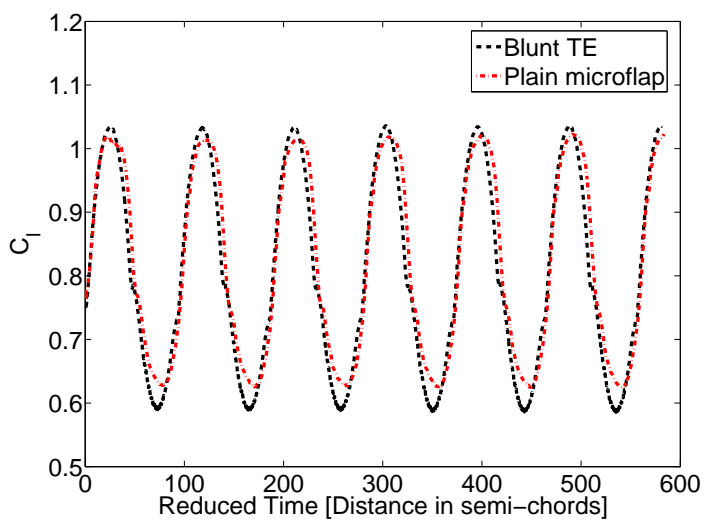

(a) Lift coefficient

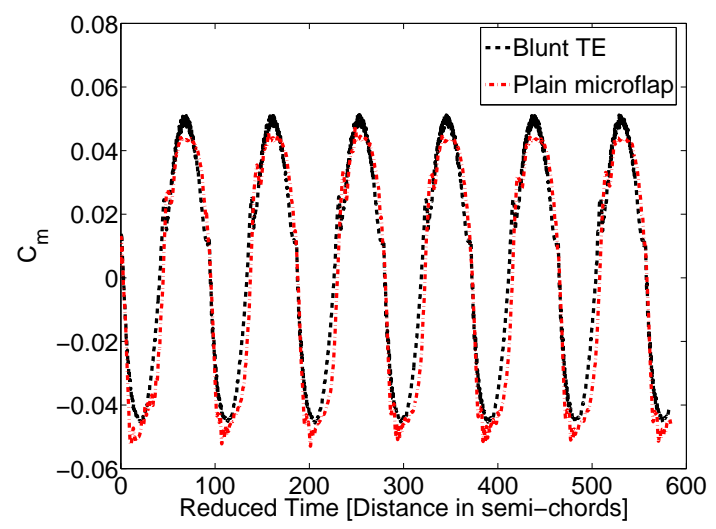

(b) Moment coefficient

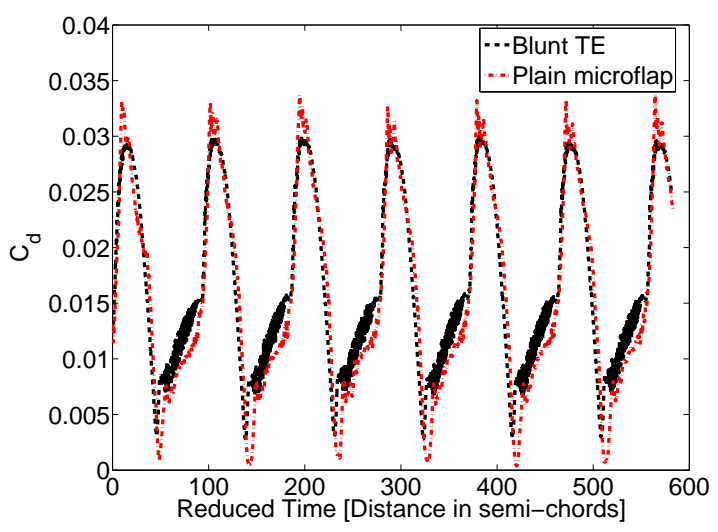

(c) Drag coefficient

Figure 17. Unsteady sectional force coefficients for both up and down microflap deflection at $\alpha=6^{\circ}$ and $\mathrm{M}=0.51$. 


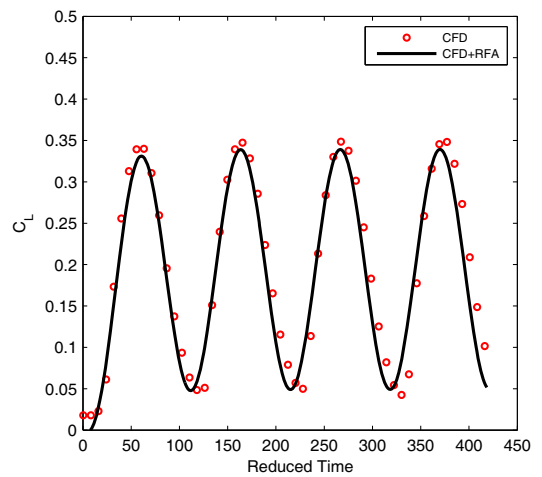

(a) lift, $\mathrm{k}=0.06$

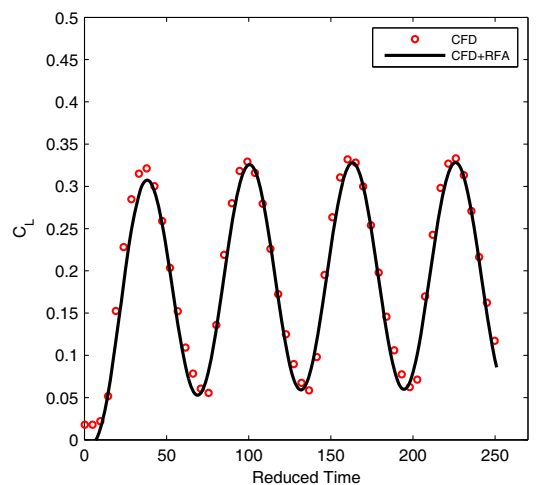

(d) lift, $\mathrm{k}=0.1$

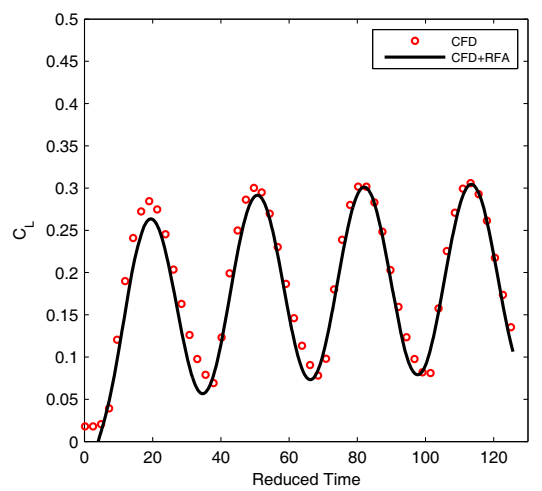

(g) lift, $\mathrm{k}=0.2$

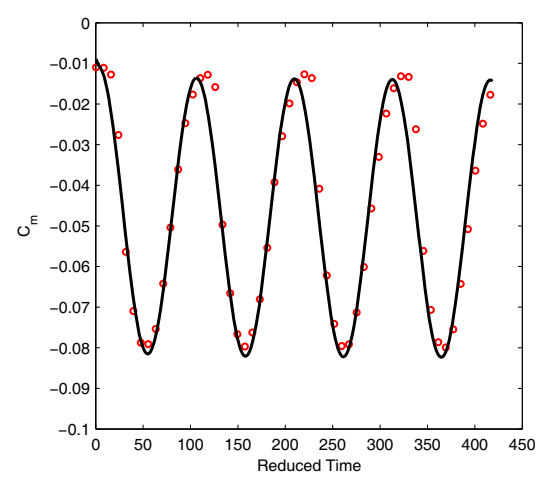

(b) moment, $\mathrm{k}=0.06$

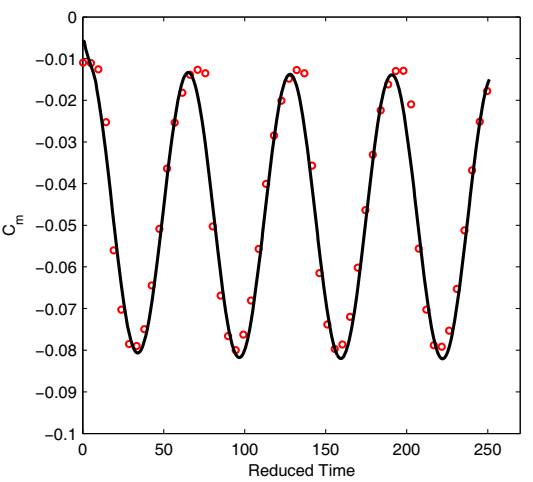

(e) moment, $\mathrm{k}=0.1$

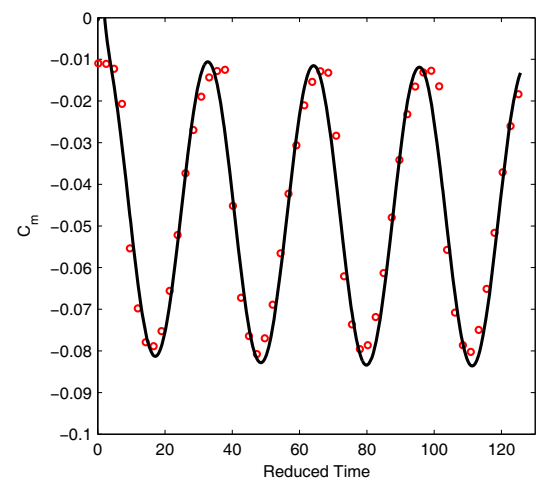

(h) moment, $\mathrm{k}=0.2$

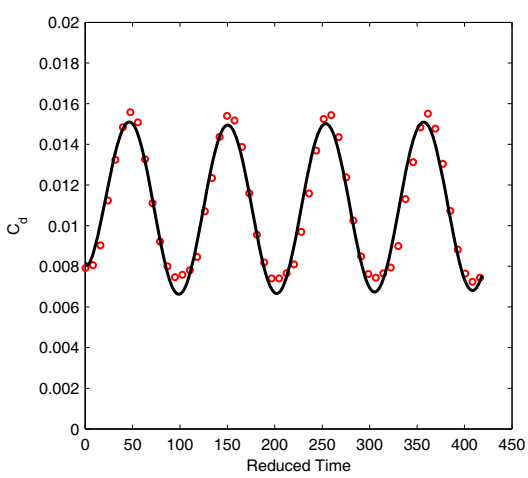

(c) drag, $\mathrm{k}=0.06$

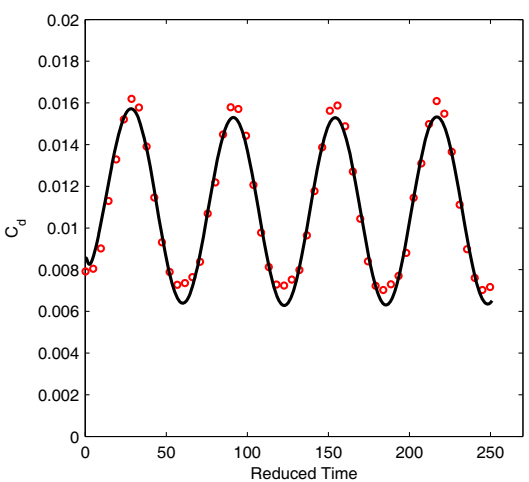

(f) drag, $\mathrm{k}=0.1$

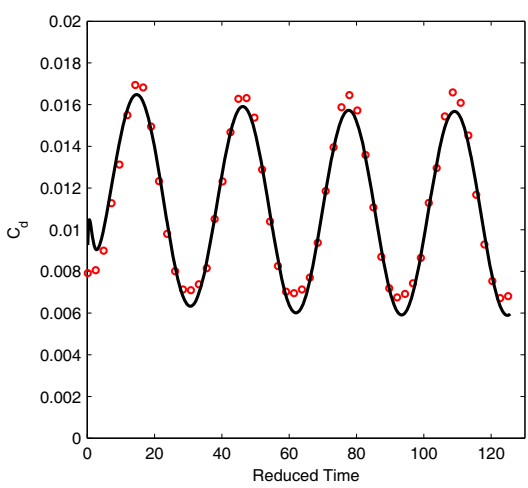

(i) drag, $\mathrm{k}=0.2$

Figure 18. Unsteady force coefficients for a $1.5 \%$ c sharp TE microflap oscillating at various reduced frequencies; $\alpha=0^{\circ}$ and $M=0.6$.

configuration considered is the sharp TE configuration. For this preliminary study, the ROMs for unsteady lift and moment due to the microflap have been incorporated into the AVINOR code ${ }^{18,24,30,31}$ in order to examine the microflap effects, while the CFD based reduced order drag model has not been implemented. The results generated give a preliminary indication of the vibration reduction capabilities of the microflap, at low advance ratios where blade vortex interaction (BVI) is important. The rotor configuration is a fourbladed hingeless rotor, resembling the MBB BO-105. The advance ratio used in the simulations is $\mu=0.15$, which corresponds to a flight condition where high vibration levels are encountered due to strong blade vortex interaction. Previous studies have been conducted using conventional actively controlled trailing edge flaps for vibration reduction. ${ }^{24,30,31}$ Therefore, one can compare in an approximate manner the vibration reduction potential of the conventional flap and microflap under similar flight conditions. In this study, a single microflap is considered which spans $12 \%$ of the blade radius, centered at $75 \% \mathrm{R}$ radial location. The spanwise size and location of the microflap configuration employed in the simulations are chosen such that 
they are identical to the single trailing edge active flap configurations considered in earlier studies. ${ }^{40}$ The rotor and microflap configurations are summarized in Table 1.

Table 1. Blade and microflap configuration.

\begin{tabular}{ll}
\hline \hline Rotor Data & \\
$N_{b}=4$ & $c=0.05498 L_{b}$ \\
$\omega_{F}=1.12,3.41,7.62$ & $\omega_{L}=0.73,4.46$ \\
$\omega_{T}=3.17$ & $C_{d 0}=0.01$ \\
$\theta_{\mathrm{tw}}=-8^{\circ}$ & $\theta_{\mathrm{FP}}=6.5^{\circ}$ \\
$\gamma=5.5$ & $\sigma=0.07$ \\
$\beta_{p}=2.5^{\circ}$ & \\
Helicopter Data & \\
$\overline{C_{T} / \sigma=0.0714}$ & $\mu=0.15$ \\
$L_{b}=4.91 \mathrm{~m}$ & $\Omega=425 \mathrm{RPM}$ \\
Microflap configuration & \\
$c_{f}=1.5 \% c$ & \\
$x_{c}=0.75 L_{b}$ & $L_{c}=0.12 L_{b}$ \\
\hline \hline
\end{tabular}

Simulation results with a microflap operating in the open loop mode were generated. An open loop phase sweep is conducted by varying the phase angle $\phi_{c}$ for four discrete oscillating frequencies corresponding to $2 / \mathrm{rev}-5 / \mathrm{rev}$, where the microflap motion is defined by

$$
\delta_{f}=0.75 \% c\left[1-\cos \left(\omega t+\phi_{c}\right)\right],
$$

Figure 19 shows the effects of each microflap harmonic on the dominant 4/rev vertical shear component. The results shown indicate the microflap control inputs significantly affect the $4 /$ rev vertical shear. This indicate that the microflap has sufficient control authority for vibration reduction. It was found that the $4 / \mathrm{rev}$ harmonic is most effective and is capable of producing maximum vibration reduction of $52 \%$ at the phase angle setting $\phi_{c}=300^{\circ}$. The $2 / \mathrm{rev}, 3 / \mathrm{rev}$ and $5 / \mathrm{rev}$ control inputs produce somewhat smaller vertical shear reduction levels, in the range of $12 \%-22 \%$. When compared to a conventional flap configuration with a servo flap having chord of $25 \%$ c, ${ }^{40}$ which produced $90 \%$ vibration reduction with $3 /$ rev harmonics, the microflap generated less amount of vibration reduction. This implies that the optimal microflap configuration for vibration reduction may be different from that used for conventional flaps.

Vibratory hub loads for the $4 / \mathrm{rev}$ microflap harmonic input at phase angle $\phi_{c}=300^{\circ}$ are shown in Fig. 20 , which corresponds to the maximum vertical shear reduction. Figure 20 shows all six components of the $4 / \mathrm{rev}$ hub loads, which consist of three hub shears and three hub moments. In addition to the $52 \%$ reduction in vertical shear, other vibratory components with the exception of yawing moment are also slightly reduced using this open loop input.

\section{Conclusions}

The aerodynamic characteristics of three different microflap configurations were studied using the RANS flow solver, CFD ++ . The unsteady characteristics of the microflap were examined by considering several reduced frequencies representative of rotorcraft applications. Sectional aerodynamic responses for an oscillating microflap were obtained considering three configurations: a) a microflap sliding in and out of a cavity on an airfoil with sharp trailing edge; b) a microflap sliding up and down at the blunt trailing edge of an airfoil; and c) a microflap resembling a plain flap configuration. The simulation results indicate that the configuration with sharp trailing edge yields the best $\mathrm{L} / \mathrm{D}$ ratio and the blunt trailing edge configuration is the worst. However, the blunt trailing edge configuration may have an advantage when considering practical implementation. Overall, the sharp trailing edge configuration may be the best compromise between the aerodynamic benefits and the ease of implementation. This configuration has a significant disadvantage due to the fact that the microflap can be deflected only downward.

A reduced order aerodynamic model for the microflap was also developed, based on frequency domain 


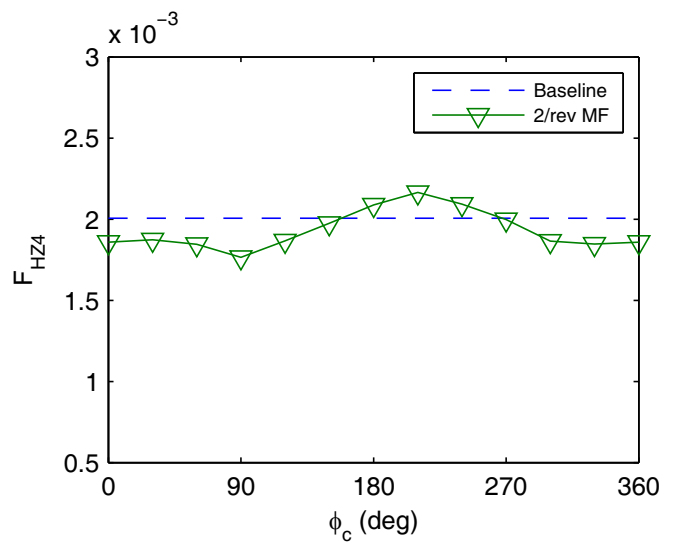

(a) $2 / \mathrm{rev}$

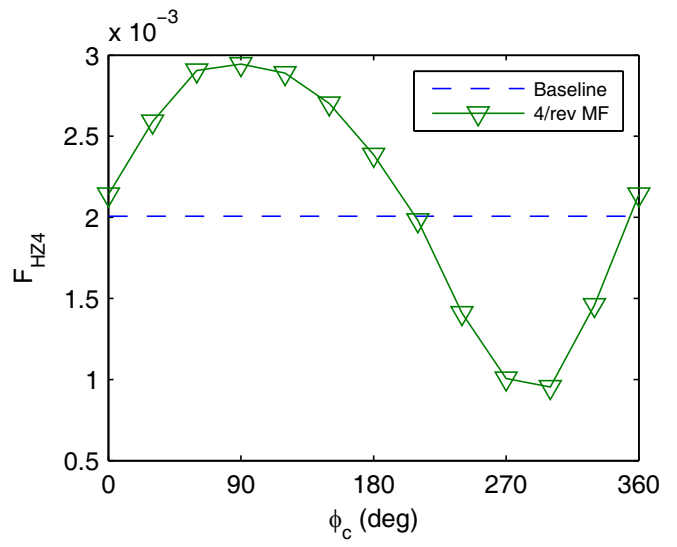

(c) $4 / \mathrm{rev}$

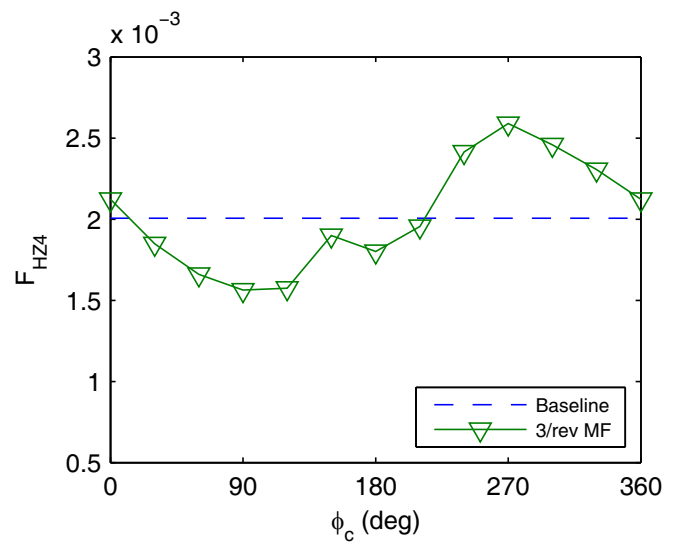

(b) $3 / \mathrm{rev}$

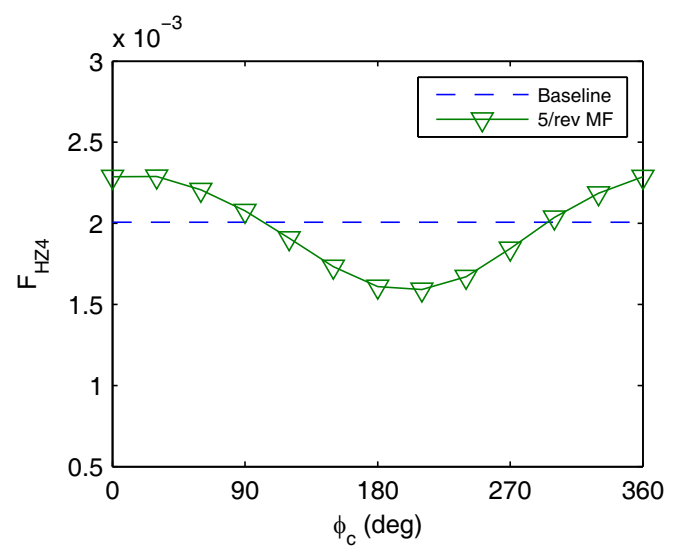

(d) $5 / \mathrm{rev}$

Figure 19. Effect of phase sweep on $4 /$ rev vertical hub shear $F_{H Z 4}$ with a $1.5 \%$ sharp TE microflap at $\mu=0.15$.

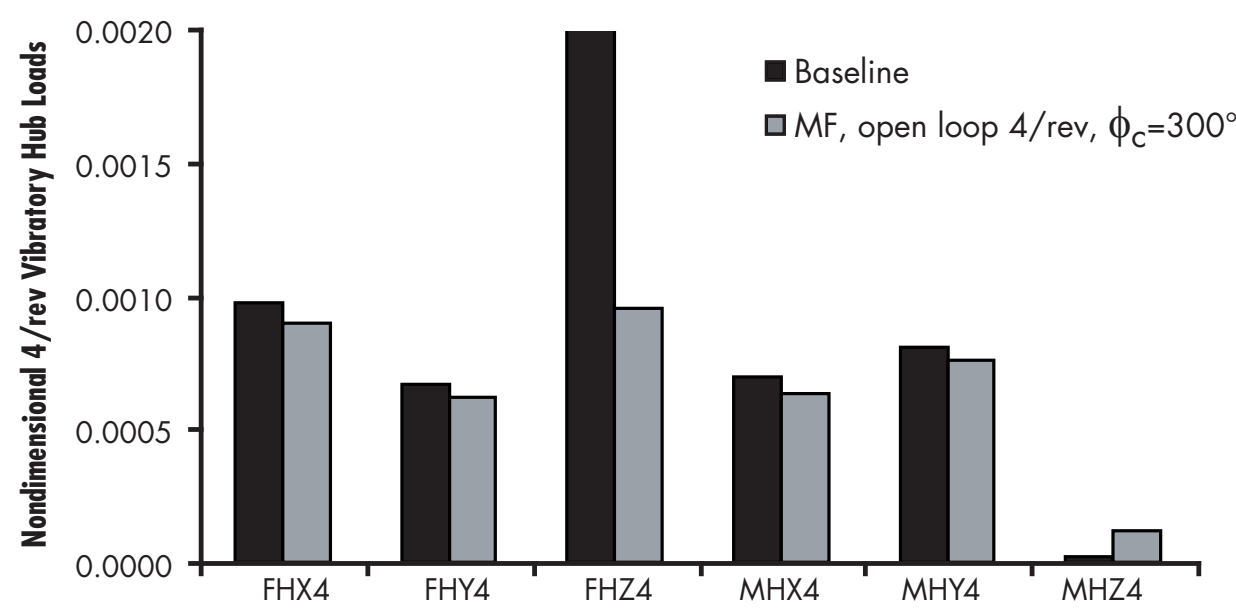

Figure 20. Vibratory loads with open loop 4/rev microflap input at $\phi_{c}=300^{\circ}$. 
responses obtained from the CFD solver. The comparisons of the aerodynamic loads between the ROM and direct CFD calculations were excellent for unsteady compressible flow conditions that are characteristic of rotorcraft aerodynamic environment, for the range of angles of attack, Mach numbers, and reduced frequencies explored in this study. The success of the CFD+RFA model in predicting efficiently and accurately the aerodynamic loading due to the microflaps, even in the presence of significant flow nonlinearities, indicates its suitability for incorporation into comprehensive rotorcraft simulation codes for investigation of the feasibility of microflaps for active control.

Preliminary studies for evaluating the control authority of the microflaps for vibration reduction in rotorcraft were also conducted, by incorporating the ROMs developed in this study into a comprehensive rotorcraft simulation code. Open loop phase sweep studies confirmed that the microflap has sufficient control authority for vibration reduction, demonstrating a maximum $52 \%$ reduction in $4 / \mathrm{rev}$ vertical shear at a high vibration BVI flight condition.

\section{Acknowledgments}

This research was supported by the Vertical Lift Research Center of Excellence (VLRCOE) sponsored by NRTC and U.S. Army with Dr. M. Rutkowski as grant monitor.

\section{References}

${ }^{1}$ Liebeck, R. H., "Design of Subsonic Airfoils for High Lift," Journal of Aircraft, Vol. 15, No. 9, Sept 1978, pp. 547-561.

${ }^{2}$ Giguere, P., Lemay, J., and Dumas, G., "Gurney Flap Effects and Scaling for Low-speed Airfoils," Proceedings of the AIAA Applied Aerodynamics Conference, San Diego, June 1995.

${ }^{3}$ Jang, C. S., Ross, J. C., and Cummings, R. M., "Numerical Investigation of an Airfoil With a Gurney Flap," Journal of Aircraft Design, Vol. 1, No. 2, June 1998, pp. 75-88.

${ }^{4}$ Baker, J. P., Standish, K. J., and van Dam, C. P., "Two-Dimensional Wind Tunnel and Computational Investigation of a Microtab Modified S809 Airfoil," Proceedings of the 43rd AIAA Aerospace Sciences Meeting and Exhibit, Reno, NV, Jan 2005, AIAA Paper No. 2005-1186.

${ }^{5}$ Chow, R. and van Dam, C. P., "Unsteady Computational Investigations of Deploying Load Control Microtabs," Journal of Aircraft, Vol. 43, No. 5, Sept-Oct 2006, pp. 641-648.

${ }^{6}$ Lee, H.-T., Kroo, I. M., and Bieniawski, S., "Flutter Suppression for High Aspect Ratio Flexible Wings Using Microflaps," Proceedings of the 43rd AIAA/ASME/ASCE/AHS/ACS Structures, Structural Dynamics and Materials Conference, Reno, NV, Apr 2002, AIAA Paper No. 2002-1717.

${ }^{7}$ Kroo, I. M., "Aerodynamic Concepts for Future Aircraft," Proceedings of the 30th AIAA Fluid Dynamics Conference, Norfolk, VA, Jun-July 1999, AIAA Paper No. 99-2003.

${ }^{8}$ Matalanis, C. G. and Eaton, J. K., "Wake Vortex Alleviation Using Rapidly Actuated Segmented Gurney Flaps," AIAA Journal, Vol. 45, No. 8, Aug. 2007, pp. 1874-1884.

${ }^{9}$ Vey, S., Paschereit, O. C., Greenblatt, D., and Meyer, R., "Flap Vortex Management by Active Gurney Flaps," Proceedings of the 46th AIAA Aerospace Sciences Meeting and Exhibit, Reno, NV, Jan 2008, AIAA Paper No. 2008-286.

${ }^{10}$ Nikolic, V. R., "Two Aspects of the Use of Full- and Partial-Span Gurney Flaps," Journal of Aircraft, Vol. 44, No. 5, Sept-Oct 2007, pp. 1745-1748.

${ }^{11}$ Kentfield, J. A. C., "The Potential of Gurney Flaps for Improving the Aerodynamic Performance of Helicopter Rotors," Proceedings of the AIAA International Powered Lift Conference, 1993, AIAA Paper No. 93-4883.

${ }^{12}$ Maughmer, M. D., Lesieutre, G. L., and Kinzel, M. P., "Miniature Trailing-Edge Effectors for Rotorcraft Performance Enhancement," Proceedings of the 61st Annual American Helicopter Society Forum, Grapevine, TX, June 2005.

${ }^{13}$ Kinzel, M. P., Maughmer, M. D., Lesieutre, G. L., and Duque, E. P. N., "Numerical Investigation of Miniature TrailingEdge Effectors on Static and Oscillating Airfoils," Proceedings of the 43rd AIAA Aerospace Sciences Meeting and Exhibit, Reno, NV, Jan 2005, AIAA Paper No. 2005-1039.

${ }^{14}$ Friedmann, P. P. and Millott, T. A., "Vibration Reduction in Rotorcraft Using Active Control: A Comparison of Various Approaches," Journal of Guidance, Control, and Dynamics, Vol. 18, No. 4, July-August 1995, pp. 664-673.

${ }^{15}$ Friedmann, P. P., de Terlizzi, M., and Myrtle, T. F., "New Developments in Vibration Reduction with Actively Controlled Trailing Edge Flaps," Mathematical and Computer Modelling, Vol. 33, 2001, pp. 1055-1083.

${ }^{16}$ Koratkar, N. A. and Chopra, I., "Wind Tunnel Testing of a Smart Rotor Model with Trailing Edge Flaps," Journal of the American Helicopter Society, Vol. 47, No. 4, Oct. 2002, pp. 263-272.

${ }^{17}$ Straub, F. K., Kennedy, D. K., Bomzalski, D. B., Hassan, A. A., Ngo, H., Anand, V. R., and Birchette, T. S., "Smart Material Actuated Rotor Technology - SMART," Journal of Intelligent Material Systems and Structures, Vol. 15, No. 4, April 2004.

${ }^{18}$ Patt, D., Liu, L., and Friedmann, P. P., "Simultaneous Vibration and Noise Reduction in Rotorcraft Using Aeroelastic Simulation," Journal of the American Helicopter Society, Vol. 51, No. 2, April 2006, pp. 127-140.

${ }^{19}$ Dieterich, O., Enenkl, B., and Roth, D., "Trailing Edge Flaps for Active Rotor Control Aeroelastic Characteristics of the ADASYS Rotor System," Proceedings of the 62nd American Helicopter Society Annual Forum, Phoenix, AZ, May 2006.

${ }^{20}$ Rogers, K. L., Airplane Math Modeling Methods for Actively Control Design, AGARD-CP-228, August 1977. 
${ }^{21}$ Edwards, J. H., "Application of Laplace Transform Methods to Airfoil Motion and Stability Calculations," Proceedings of the 20th Structures, Structural Dynamics and Materials Conference, St. Louis, MO, April 1979, AIAA Paper No. $1979-772$.

${ }^{22}$ Karpel, M., Design for Active and Passive Flutter Suppression and Gust Alleviation, NASA Contractor Report 3492, Nov. 1981.

${ }^{23}$ Vepa, R., Finite State Modeling of Aeroelastic Systems, NASA Contractor Report 2779, 1977.

${ }^{24}$ Myrtle, T. F. and Friedmann, P. P., "Application of a New Compressible Time Domain Aerodynamic Model to Vibration Reduction in Helicopters Using an Actively Controlled Flap," Journal of the American Helicopter Society, Vol. 46, No. 1, Jan. 2001, pp. 32-43.

${ }^{25}$ Liu, L., Friedmann, P. P., Kim, I., and Bernstein, D. S., "Rotor Performance Enhancement and Vibration Reduction in Presence of Dynamic Stall Using Actively Controlled Flaps," Journal of the American Helicopter Society, Vol. 53, No. 4, October 2008, pp. 338-350.

${ }^{26}$ Peroomian, O., Chakravarthy, S., Palaniswamy, S., and Goldberg, U., "Convergence Acceleration for Unified-Grid Formulation Using Preconditioned Implicit Relaxation," AIAA Paper 98-0116, Reno, NV, January 1998.

${ }^{27}$ Peroomian, O., Chakravarthy, S., and Goldberg, U., "A "Grid-Transparent" Methodology for CFD," AIAA Paper 970724, Reno, NV, January 1997.

${ }^{28}$ Chakravarthy, S. R. and Osher, S., "New Class of High Accuracy TVD Schemes for Hyperbolic Conservation Laws," Proceedings of the 23rd AIAA Aerospace Sciences Meeting and Exhibit, Reno, NV, Jan 1985, AIAA Paper No. 85-0363.

${ }^{29}$ Thiel, M. R., Lesieutre, G. A., Maughmer, M. D., and Koopmann, G. H., "Actuation of an Active Gurney Flap for Rotorcraft Applications," 47th AIAA/ASME/ASCHE/AHS/ASC Structures, Structural Dynamics E Materials Conference, Newport, RI, May 1-4 2006, pp. 1-11, AIAA Paper 2006-2181.

${ }^{30}$ Millott, T. A. and Friedmann, P. P., Vibration Reduction in Helicopter Rotors Using an Actively Controlled Partial Span Trailing Edge Flap Located on the Blade, NASA CR 4611, June 1994.

${ }^{31}$ de Terlizzi, M. and Friedmann, P. P., "Active Control of BVI Induced Vibrations Using a Refined Aerodynamic Model and Experimental Correlation," American Helicopter Society 55th Annual Forum Proceedings, Montreal, Canada, May 25-27 1999, pp. 599-615.

${ }^{32}$ Liu, L., Friedmann, P. P., and Padthe, A. K., "Comparison of Approximate Time Domain Aerodynamics for Flapped Airfoils with CFD Based Results with Applications," Proceedings of the AHS Specialists' Conference on Aeromechanics, San Francisco, CA, January 2008.

${ }^{33}$ Liu, L., Friedmann, P. P., and Padthe, A. K., "An Approximate Unsteady Aerodynamic Model for Flapped Airfoils Including Improved Drag Predictions," Proceedings of the 34th European Rotorcraft Forum, Liverpool, UK, September 2008.

${ }^{34}$ Rodden, W. P. and Albano, E., "A Doublet-Lattice Method for Calculating Lift Distributions on Oscillating Surfaces in Subsonic Flows," AIAA Journal, Vol. 7, No. 2, Feb. 1969, pp. 279-285.

${ }^{35}$ Bisplinghoff, R. L., Ashley, H., and Halfman, R., Aeroelasticity,, chap. 6, Addison-Wesley, 1955, pp. 317-325.

${ }^{36}$ Allwine, D. A., Strahler, J. A., Lawrence, D. A., Jenkins, J. E., and Myatt, J. H., "Nonlinear Modeling of Unsteady Aerodynamics at High Angle of Attack," Proceedings of the AIAA Atmospheric Flight Mechanics Conference and Exhibit, Providence, RI, Aug 2004.

${ }^{37}$ Lee, D., Leishman, J. G., and Baeder, J. D., "A Nonlinear Indicial Method for the Calculation of Unsteady Airloads," Proceedings of the 59th American Helicopter Society Annual Forum, Phoenix, AZ, May 2003.

${ }^{38}$ Menter, F. R., "Two-equation Eddy-Viscosity Turbulence Models for Engineering Applications," AIAA Journal, Vol. 32, No. 8, Aug 1994, pp. 1598-1605.

${ }^{39}$ Jeffrey, D., Zhang, X., and Hurst, D. W., "Aerodynamics of Gurney Flaps on a Single-Element High-Lift Wing," Journal of Aircraft, Vol. 37, No. 2, 2000, pp. 295-301.

${ }^{40}$ Patt, D., Liu, L., and Friedmann, P. P., "Active Flaps for Noise Reduction: A Computational Study," American Helicopter Society 61st Annual Forum Proceedings, Grapevine, TX, June 1-3, 2005. 